Atmos. Chem. Phys., 14, 3231-3246, 2014

www.atmos-chem-phys.net/14/3231/2014/

doi:10.5194/acp-14-3231-2014

(c) Author(s) 2014. CC Attribution 3.0 License.

\title{
Arctic stratospheric dehydration - Part 2: Microphysical modeling
}

\author{
I. Engel ${ }^{1, *}$, B. P. Luo ${ }^{1}$, S. M. Khaykin ${ }^{2,3}$, F. G. Wienhold ${ }^{1}$, H. Vömel ${ }^{4}$, R. Kivi ${ }^{5}$, C. R. Hoyle ${ }^{6,7}$, J.-U. Grooß ${ }^{8}$, \\ M. C. Pitts ${ }^{9}$, and T. Peter ${ }^{1}$ \\ ${ }^{1}$ Institute for Atmospheric and Climate Science, ETH Zurich, Zurich, Switzerland \\ ${ }^{2}$ Central Aerological Observatory, Dolgoprudny, Moscow Region, Russia \\ ${ }^{3}$ LATMOS-IPSL, Université Versailles St. Quentin, CNRS/INSU, Guyancourt, France \\ ${ }^{4}$ Deutscher Wetterdienst, Meteorological Observatory Lindenberg - Richard Aßmann Observatory, Lindenberg, Germany \\ ${ }^{5}$ Finnish Meteorological Institute, Arctic Research, Sodankylä, Finland \\ ${ }^{6}$ Laboratory of Atmospheric Chemistry, Paul Scherrer Institute, Villigen, Switzerland \\ ${ }^{7}$ Swiss Federal Institute for Forest Snow and Landscape Research (WSL) - Institute for Snow and Avalanche Research (SLF), \\ Davos, Switzerland \\ ${ }^{8}$ Institut für Energie- und Klimaforschung - Stratosphäre (IEK-7), Forschungszentrum Jülich, Jülich, Germany \\ ${ }^{9}$ NASA Langley Research Center, Hampton, Virginia, USA \\ *now at: Institut für Energie- und Klimaforschung - Stratosphäre (IEK-7), Forschungszentrum Jülich, Jülich, Germany
}

Correspondence to: I. Engel (ines.engel@alumni.ethz.ch)

Received: 13 August 2013 - Published in Atmos. Chem. Phys. Discuss.: 18 October 2013

Revised: 14 February 2014 - Accepted: 18 February 2014 - Published: 2 April 2014

\begin{abstract}
Large areas of synoptic-scale ice PSCs (polar stratospheric clouds) distinguished the Arctic winter 2009/2010 from other years and revealed unprecedented evidence of water redistribution in the stratosphere. A unique snapshot of water vapor repartitioning into ice particles was obtained under extremely cold Arctic conditions with temperatures around $183 \mathrm{~K}$. Balloon-borne, aircraft and satellitebased measurements suggest that synoptic-scale ice PSCs and concurrent reductions and enhancements in water vapor are tightly linked with the observed de- and rehydration signatures, respectively. In a companion paper (Part 1), water vapor and aerosol backscatter measurements from the RECONCILE (Reconciliation of essential process parameters for an enhanced predictability of Arctic stratospheric ozone loss and its climate interactions) and LAPBIAT-II (Lapland Atmosphere-Biosphere Facility) field campaigns have been analyzed in detail. This paper uses a column version of the Zurich Optical and Microphysical box Model (ZOMM) including newly developed NAT (nitric acid trihydrate) and ice nucleation parameterizations. Particle sedimentation is calculated in order to simulate the vertical redistribution of chemical species such as water and nitric acid. Despite limitations given by wind shear and uncertainties in the initial water vapor profile, the column modeling unequivocally
\end{abstract}

shows that (1) accounting for small-scale temperature fluctuations along the trajectories is essential in order to reach agreement between simulated optical cloud properties and observations, and (2) the use of recently developed heterogeneous ice nucleation parameterizations allows the reproduction of the observed signatures of de- and rehydration. Conversely, the vertical redistribution of water measured cannot be explained in terms of homogeneous nucleation of ice clouds, whose particle radii remain too small to cause significant dehydration.

\section{Introduction}

Polar stratospheric clouds (PSCs) may form in the lower stratosphere above the winter poles at sufficiently low temperatures. Ice PSCs require the coldest conditions, with temperatures about $3 \mathrm{~K}$ below the frost point $\left(T_{\text {frost }}\right)$ to nucleate ice particles homogeneously (Koop et al., 2000). When the particles grow to sizes large enough to sediment, dehydration may occur, that is, the irreversible redistribution of water vapor, as frequently observed above the Antarctic (e.g., Kelly et al., 1989; Vömel et al., 1995; Nedoluha et al., 2000). Temperatures in the Arctic stratosphere are generally warmer 
than in the Antarctic stratosphere and therefore the formation of ice PSCs and the occurrence of dehydration events is relatively infrequent. Some observations of ice PSCs and water vapor depleted regions from the coldest Arctic winters are published in the literature (e.g., Fahey et al., 1990; Vömel et al., 1997; Jimenez et al., 2006; Maturilli and Dörnbrack, 2006). However, these studies did not observe such a clear case of vertical redistribution of water vapor as that presented here, which occurred above Sodankylä during the Arctic winter 2009/2010.

This paper presents vertical profiles of water vapor and aerosol backscatter obtained within the framework of the LAPBIAT-II (Lapland Atmosphere-Biosphere Facility) balloon campaign in January 2010 from Sodankylä, Finland, which was closely related to the RECONCILE (Reconciliation of essential process parameters for an enhanced predictability of Arctic stratospheric ozone loss and its climate interactions) project and its activities in the same Arctic winter (von Hobe et al., 2013). Whereas the majority of Arctic PSC studies describe wave ice cloud observations above Scandinavia (e.g., Carslaw et al., 1998b; Fueglistaler et al., 2003), we present model simulations based on observations of rare synoptic-scale ice clouds. A week-long period (15 to 21 January 2010) of unusually cold temperatures at stratospheric levels led to the formation of synoptic-scale ice PSCs (Pitts et al., 2011). Balloon-borne measurements of particle backscatter and water vapor on 17 January captured an ice PSC and the concurrent uptake of water from the gas phase in fine detail, providing a high-resolution snapshot of the process of ice PSC formation. A vertical redistribution of water inside the vortex, which was tracked remotely and could be quantified again by in situ measurements some five days later, was observed in the Arctic stratosphere for the first time. A companion paper (Khaykin et al., 2013) presents the series of in situ observations in January 2010 above Sodankylä, which coincide with vortex-wide satellite measurements. This study connects two individual balloon soundings by trajectories and simulates the formation, growth and sedimentation of the ice particles.

Very recently, the commonly accepted theories describing the formation mechanisms of PSCs have been revised. Homogeneous freezing of supercooled ternary solution (STS) droplets is the generally accepted formation pathway for ice PSCs, requiring a supercooling of $T \lesssim T_{\text {frost }}-3 \mathrm{~K}$ (e.g., Koop et al., 1995, 2000). The importance of heterogeneous ice nucleation for PSC formation was shown by Engel et al. (2013), together with a study by Hoyle et al. (2013), which reconciled the current theory of nitric acid trihydrate (NAT) nucleation with observed PSC characteristics.

This study uses a column version of the Zurich Optical and Microphysical box Model (ZOMM) including the newly developed NAT and ice nucleation parameterizations. Similar to the one-dimensional version of ZOMM, the new column version allows the simulation of the nucleation and growth of PSC particles and the associated reduction in water vapor.
Additionally, because sedimentation is included, the column version can be used to follow trajectories over longer periods of time and thus allows the simulation of the observed dehydration of the Arctic stratosphere. Caveats of this method will be discussed in Sect. 2.4.1.

In this study, we examine the effect of different nucleation mechanisms, in particular homogeneous vs. heterogeneous ice formation, as well as temperature fluctuations, on PSC properties. The overall goal of this work is to compare the modeled microphysics with the observations and thus test the newly proposed heterogeneous ice nucleation parameterizations. We show that in order to successfully reproduce the observed dehydration and rehydration, heterogeneous nucleation and temperature fluctuations must be accounted for in the model.

\section{Methods}

The following section provides a short overview of the measurement techniques used to obtain the data for this study. Furthermore, the trajectory calculation tool and the microphysical column model are characterized. A more comprehensive description of the different instruments is given in the companion paper by Khaykin et al. (2013).

\subsection{Backscatter measurements}

Backscatter measurements from balloon- and spaceborne instruments are utilized in this work. The Compact Optical Backscatter Detector (COBALD) is a backscatter sonde, engineered at ETH Zurich, complementing operational weather balloon payloads. The sonde is a follow-up development of the backscatter sonde designed by Rosen and Kjome (1991). Two LEDs emitting at wavelengths of $455 \mathrm{~nm}$ and $870 \mathrm{~nm}$ are aligned in parallel and located to the left and right of a silicon detector. The light scattered back by air molecules, aerosols and cloud particles is recorded with a typical frequency of $1 \mathrm{~Hz}$. The data analysis follows Rosen and Kjome (1991) to separate the individual contributions from molecules and aerosols to the measured backscatter signal. The molecular air number density is derived from temperature and pressure recorded simultaneously by the radiosonde hosting COBALD. A direct indicator for the presence of aerosols is the backscatter ratio (BSR): it is defined as the ratio of the total (aerosol and molecular) to the molecular backscattered light intensity (at $\sim 180^{\circ}$ back to the detector). Accordingly, the aerosol backscatter ratio is equal to BSR - 1. COBALD has already been applied in several different field studies, for example, measuring the volcanic aerosol plume after the eruption of the Eyjafjallajökull (Bukowiecki et al., 2011) and cirrus clouds (Brabec et al., 2012; Cirisan et al., 2013).

The Cloud-Aerosol Lidar and Infrared Pathfinder Satellite Observations (CALIPSO) satellite provides profiling measurements of cloud and aerosol distribution and properties 
obtained by the Cloud-Aerosol Lidar with Orthogonal Polarization (CALIOP). The satellite completes 14.5 orbits per day and has a near-global coverage, ranging from $82^{\circ} \mathrm{N}$ to $82^{\circ} \mathrm{S}$ (Winker et al., 2007). CALIPSO's orbit inclination and its associated extensive polar coverage make the satellite an ideal platform for PSC observations. For this purpose, Pitts et al. $(2007,2009)$ introduced a detection algorithm to identify and further classify PSCs. Their composition classification is based on BSR at a wavelength of $532 \mathrm{~nm}$ and aerosol depolarization $\left(\delta_{\text {aerosol }}\right)$ obtained from the CALIOP Level 1B data product. The data is averaged to a uniform grid with a horizontal resolution of $5 \mathrm{~km}$ and a vertical resolution of $180 \mathrm{~m}$. Pitts et al. (2011) distinguish six different PSC composition classes with varying number densities of liquid, NAT and ice particles.

\subsection{Water vapor and nitric acid measurements}

Balloon-borne water vapor measurements are obtained by two different techniques. The Fluorescence Lyman-Alpha Stratospheric Hygrometer for Balloons (FLASH-B) is a Russian water vapor instrument developed at the Central Aerological Observatory (Yushkov et al., 1998). The fluorescence method uses the photodissociation of $\mathrm{H}_{2} \mathrm{O}$ molecules exposed to Lyman-alpha radiation followed by the measurement of the fluorescence of the resulting excited $\mathrm{OH}$ radicals (Kley and Stone, 1978). The intensity of the fluorescent light sensed by the photomultiplier is directly proportional to the water vapor mixing ratio under stratospheric conditions $(10 \mathrm{hPa}$ to $150 \mathrm{hPa})$. The second instrument used within this study is the Cryogenic Frost point Hygrometer (CFH), which was developed at the University of Colorado (Vömel et al., 2007a). The instrument's principle is based on a chilled mirror. The temperature of the mirror can be regulated such that a thin but constant layer of frozen condensate covers the surface. The thickness of the frozen layer is controlled by a photodiode connected to an LED. The photodiode measures variations of the reflected light caused by changes in the thickness of the condensate, which feeds back into the regulation of the mirror temperature. Under these conditions, $T_{\text {frost }}$ of the surrounding air is equal to the mirror temperature. The reported overall uncertainty, which includes accuracy and precision, for both instruments in the middle stratosphere is less than $10 \%$ (Vömel et al., 2007b).

Water vapor and nitric acid were measured using the Microwave Limb Sounder (MLS) aboard the Aura satellite. MLS provides atmospheric profiles of temperature and composition (including $\mathrm{H}_{2} \mathrm{O}$ and $\mathrm{HNO}_{3}$ ) via passive measurement of microwave thermal emission from the limb of the Earth's atmosphere (Waters et al., 2006). Vertical scans are performed every $25 \mathrm{~s}$, corresponding to a distance of $165 \mathrm{~km}$ along the orbit track. Vertical and horizontal along-track resolutions are $3.1 \mathrm{~km}$ to $3.5 \mathrm{~km}$ and $180 \mathrm{~km}$ to $290 \mathrm{~km}$, respectively, for $\mathrm{H}_{2} \mathrm{O}$, and $3.5 \mathrm{~km}$ to $5.5 \mathrm{~km}$ and $400 \mathrm{~km}$ to $550 \mathrm{~km}$ for $\mathrm{HNO}_{3}$. Aura flies in formation with CALIPSO in the A- train satellite constellation and CALIOP and MLS measurement tracks are closely aligned. The spatial and temporal differences are less than $10 \mathrm{~km}$ and $30 \mathrm{~s}$ after a repositioning of the Aura satellite in April 2008 (Lambert et al., 2012). MLS water vapor profiles presented in this study are interpolated to the CALIOP PSC grid using a weighted average of the two nearest MLS profiles (Pitts et al., 2013). Typical single-profile precisions of the MLS version 3.3 measurements (Livesey et al., 2011) are $4 \%$ to $15 \%$ for $\mathrm{H}_{2} \mathrm{O}$ (Read et al., 2007; Lambert et al., 2007) and $0.7 \mathrm{ppbv}$ for $\mathrm{HNO}_{3}$ (Santee et al., 2007).

\subsection{Trajectory calculations}

The trajectories used within this study are calculated from six-hourly wind and temperature fields of the ERA-Interim reanalysis produced by the European Centre for MediumRange Weather Forecasts (ECMWF) (Dee et al., 2011), with a horizontal resolution of $1^{\circ} \times 1^{\circ}$. We used the trajectory module of the Chemical Lagrangian Model of the Stratosphere (CLaMS) (McKenna et al., 2002) to calculate trajectories for the microphysical study. Vertical velocities are derived from ERA-Interim total diabatic heating rates (Ploeger et al., 2010). Starting at 19:47 UTC on 17 January 2010, a balloon sounding was performed from Sodankylä (hereafter referred to as S1). Individual balloon positions along its pathway at pressure levels $<100 \mathrm{hPa}$ served as start points for the first set of trajectory calculations. With a vertical distance of $100 \mathrm{~m}$ between two trajectories, two-day backward and three-day forward trajectories with time steps of $15 \mathrm{~min}$ were computed. A second sonde was launched on 23 January 2010 at 17:30 UTC (hereafter referred to as S2), for which three-day backward and two-day forward trajectories in the same altitude range as for the first sounding have been calculated. Figure 1 illustrates the pathways of two exemplary trajectories for each sounding within the Arctic vortex. It is apparent that Sodankylä was located in the cold pool with temperatures as low as $183 \mathrm{~K}$ as measured by the sondes, while upstream the air was more than $10 \mathrm{~K}$ warmer. On 17 January Sodankylä was at the edge of a larger area of synoptic-scale ice clouds seen by CALIOP.

Pressure and temperature from the joined backward and forward trajectories constitute the meteorological input for the microphysical model. Additionally, information about total water and nitric acid mixing ratios is needed at the upstream end of the trajectories. For $\mathrm{S} 1, \mathrm{HNO}_{3}$ values were taken from MLS, averaged for the corresponding day over cloud-free areas within the vortex and vertically interpolated to the starting pressure of the trajectories. Vertically resolved climatological mean values for January were used as $\mathrm{H}_{2} \mathrm{O}$ input. The $\mathrm{H}_{2} \mathrm{O}$ profile is calculated from ice-cloud-free measurements conducted above Sodankylä, between 2002 and 2010, using the National Oceanic and Atmospheric Administration (NOAA) frost point hygrometer and the CFH (see Khaykin et al., 2013, for more details). Simulations of S2 


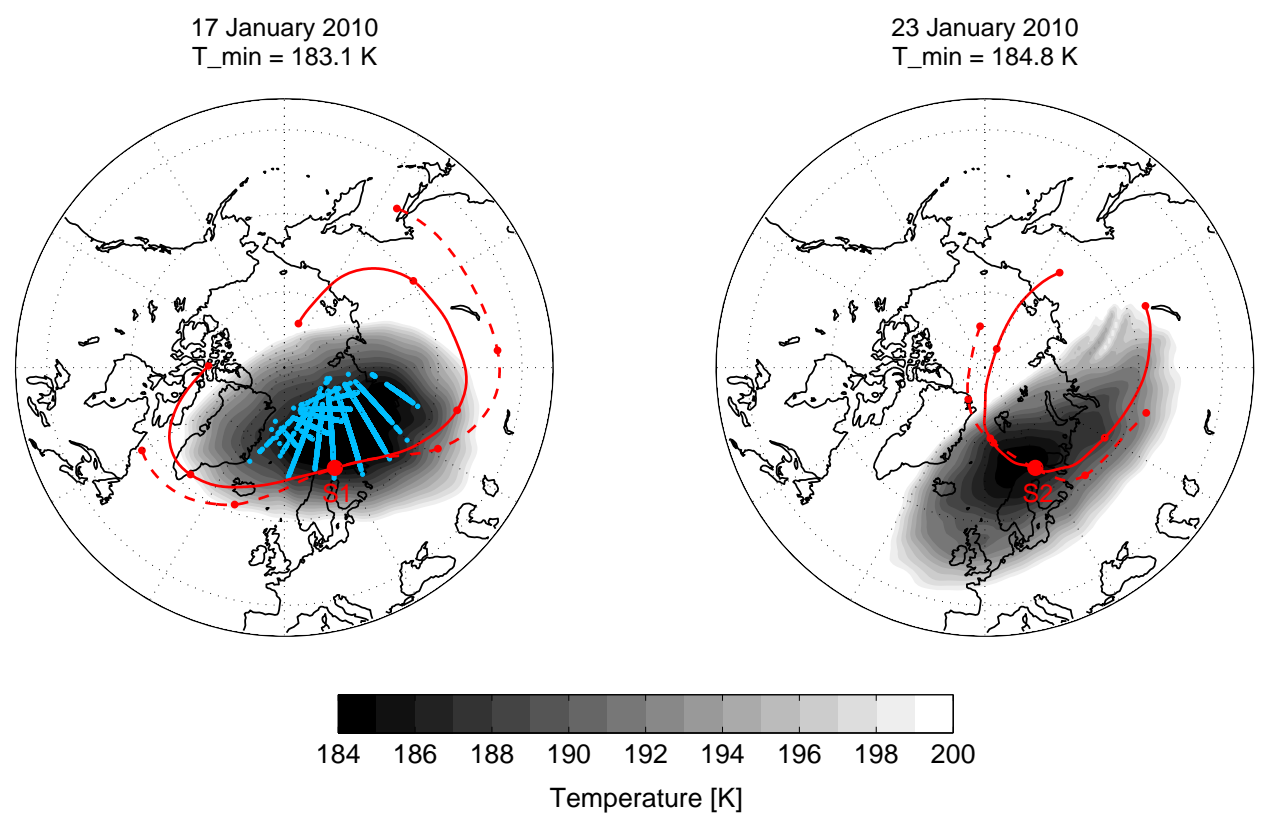

Fig. 1. Polar maps with ERA-Interim temperatures at $30 \mathrm{hPa}$ (grayscale) on 17 January 2010 (left) and 23 January 2010 (right). Red curves: CLaMS trajectories starting on these day above Sodankylä at $520 \mathrm{~K}$ (solid) and $440 \mathrm{~K}$ (dashed) potential temperature. Trajectories are two days backward and three days forward in time for 17 January 2010 (S1) and three days backward and two days forward in time for 23 January 2010 (S2). Red dots: $24 \mathrm{~h}$ time periods along the trajectories. Cyan points: ice clouds observed by CALIOP on 17 and 18 January 2010 between $16 \mathrm{~km}$ and $30 \mathrm{~km}$ altitude. No ice clouds were observed by CALIOP on 23 January 2010.

were initialized with the $\mathrm{H}_{2} \mathrm{O}$ and $\mathrm{HNO}_{3}$ profiles from $\mathrm{S} 1$ at $t=21$ days. Even though a horizontal displacement exists between the individual trajectory end and start points of S1 and S2, respectively, the approach is justified given the temperature distribution on vortex scale: at points where trajectories are matched, temperatures were above $200 \mathrm{~K}$, ensuring cloud-free air and thus no change in the $\mathrm{H}_{2} \mathrm{O}$ distribution.

Trajectory temperatures were corrected according to Fig. 2, showing temperature deviations between ERAInterim reanalysis data and measurements, taken by the Vaisala RS-92 on S1. The total measurement uncertainty for the temperature sensor is $0.5 \mathrm{~K}$ with an accuracy of $0.3 \mathrm{~K}$ between $100 \mathrm{hPa}$ and $20 \mathrm{hPa}$ as specified by Vaisala. Between $32 \mathrm{hPa}$ and $25 \mathrm{hPa}$, ERA-Interim temperatures were more than $1.5 \mathrm{~K}$ too warm compared to the measured temperatures. The temperature deviation coincides with the observed ice cloud, which cannot be reproduced using original ERA-Interim temperatures, as shown below. Assuming that the temperature difference is caused by a local cold pool not resolved in the ERA-Interim data, temperatures along the trajectories were changed only within a short time window around the observation. The amplitude of the applied temperature correction is assumed to decrease (using a sine curve) with increasing time from the observation (vertical red line in Fig. 2c) and equals zero $12 \mathrm{~h}$ before and after the observation. Figure $2 \mathrm{c}$ illustrates an exemplary trajectory without (black dashed line) and with (red solid line) applied temperature correction. In the absence of better knowledge, the max- imum amplitude is assumed to occur at the sonde flight path and is assumed to be altitude dependent as shown in Fig. $2 b$ (red line).

\subsubsection{Small-scale temperature fluctuations}

Earlier studies (e.g., Murphy and Gary, 1995; Kärcher and Lohmann, 2003; Hoyle et al., 2005) have investigated the effect of rapid temperature fluctuations and associated high cooling rates on ice cloud formation and properties. Cooling rates of less than one Kelvin per hour favor the growth of preexisting ice particles and the total number densities of ice particles remain low. In contrast, high cooling rates of several Kelvin per hour can produce supersaturations high enough to impact ice nucleation and freeze a major fraction of the stratospheric background aerosol. Gary (2006) found that a significant component of the short-term vertical displacements of isentropic surfaces remains unresolved also by current numerical weather prediction models. Recent microphysical modeling studies confirmed the importance of an adequate representation of cooling rates for cirrus (Brabec et al., 2012; Cirisan et al., 2013) and polar stratospheric clouds (Engel et al., 2013). We follow the same approach chosen in these studies and make use of the vertical velocity and temperature time series obtained from the SUCCESS (Subsonic Aircraft: Contrail and Cloud Effects Special Study) data analyzed by Hoyle et al. (2005) to conduct model runs along trajectories with superimposed temperature 

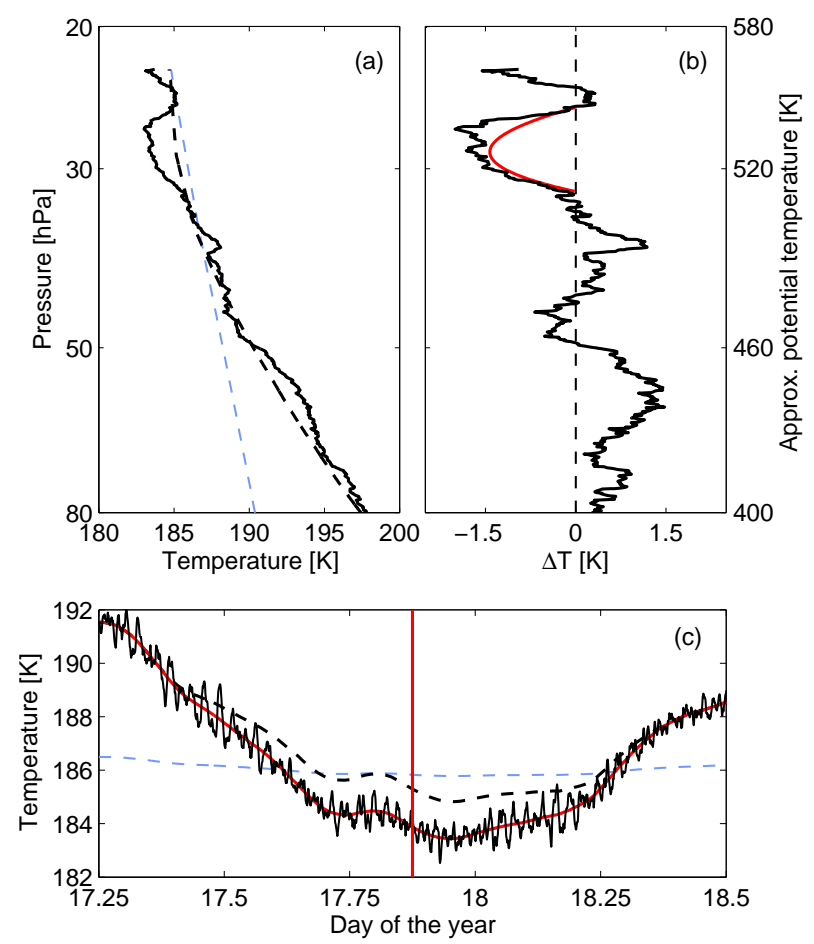

Fig. 2. (a) Black solid line: temperatures measured with the Vaisala RS-92 radiosonde launched from Sodankylä on 17 January 2010 (S1). Black dashed line: ERA-Interim reanalysis temperatures interpolated in time and space to the position of the drifting balloon. Blue dashed line: frost point temperature calculated from the climatological mean water vapor profile. (b) Difference between measurement and ERA-Interim as shown in (a). Red line: temperature correction applied to the trajectories between $32 \mathrm{hPa}$ and $25 \mathrm{hPa}$. (c) Black dashed line: exemplary ERA-Interim trajectory at S1 for $29 \mathrm{hPa}$. Blue dashed line: frost point temperature calculated from the climatological mean water vapor profile. Red solid line: ERAInterim trajectory with temperature correction. Black solid line: ERA-Interim trajectory with temperature correction and superimposed small-scale fluctuations. See text for details.

fluctuations. Only wavelengths $<400 \mathrm{~km}$ were considered, which are not resolved in the ERA-Interim wind fields used in our trajectory calculations. The temperature fluctuations were superimposed onto the synoptic-scale trajectories with random frequencies and a temporal resolution of $1 \mathrm{~s}$ as seen in Fig. 2c (black solid line). Typical peak-to-peak fluctuations are about $1 \mathrm{~K}$. Following Gary (2006), the Gaussian's "full-width at half-maximum" of a temperature differences histogram is $1.2 \mathrm{~K}$.

\subsection{Microphysical column model}

The new column version of ZOMM with implemented heterogeneous ice and NAT nucleation rates is used to simulate the formation, evolution and sedimentation of ice particles along trajectories. The underlying model, utilized for PSC simulations, has been described by Meilinger et al. (1995) and Luo et al. (2003b) and recently extended by Hoyle et al. (2013) and Engel et al. (2013). The following section provides an overview of the modifications made to ZOMM for the purposes of this study.

ZOMM can be initialized with a lognormally distributed population of supercooled binary solution (SBS) droplets, described by a mode radius, number density and distribution width, typical for winter polar stratospheric background conditions (Dye et al., 1992). Driven by temperature and pressure data along trajectories, the uptake and release of nitric acid and water in ternary solution droplets is determined. The total amounts of $\mathrm{H}_{2} \mathrm{O}, \mathrm{H}_{2} \mathrm{SO}_{4}$ and $\mathrm{HNO}_{3}$ contained in the air parcel are set at the beginning of the trajectory. A mixing of air parcels is not possible and therefore the sum of the gas and particle phase remains constant unless sedimentation takes place. The mass of sedimenting NAT and ice particles is conserved as described below. Distributed across 26 radius bins when the model is initialized, droplets are henceforward allowed to grow and shrink in a fully kinetic treatment and without being restricted to the initial lognormal shape of the distribution (Meilinger et al., 1995). The formation of solid particles results in an initiation of additional size bins. Homogeneous ice nucleation in STS droplets is calculated as is heterogeneous nucleation of ice on foreign nuclei and NAT surfaces. NAT nucleation is implemented as deposition nucleation on ice particles and as immersion freezing on foreign nuclei. Whereas homogeneous ice nucleation, following Koop et al. (2000), and NAT nucleation on uncoated ice surfaces, described in detail in Luo et al. (2003b), have been accepted pathways of PSC formation for many years now, the possibility of PSC formation via heterogeneous ice and NAT nucleation on foreign nuclei (e.g., Tolbert and Toon, 2001; Drdla et al., 2002; Voigt et al., 2005) had until previously only a narrow observational data basis so that definitive conclusions about nucleation rates were not possible; furthermore, any clear support from laboratory measurements was lacking (see detailed discussion by Peter and Grooß, 2012). The observational impasse has been overcome recently by the wealth of CALIOP PSC observations on NAT and ice PSCs obtained in the winter 2009/2010 (Pitts et al., 2011), which unmistakably reveals that both particle types must have nucleated heterogeneously. A heterogeneous nucleation mechanism, occurring on preexisting particle surfaces, for example, on meteoritic particles, has been developed to explain CALIOP PSC observations over the Arctic in December 2009 and January 2010. The parameterizations, based on active site theory (Marcolli et al., 2007), for NAT and ice are given in Hoyle et al. (2013) and Engel et al. (2013), respectively. These studies used ZOMM in a pure box model configuration, and limitations caused by neglecting sedimentation of NAT and ice particles in the winter polar stratosphere were already pointed out by these authors.

For the present study, we developed the stratospheric version of ZOMM further into a column model similar to the existing cirrus column version of ZOMM (e.g., Luo et al., 
2003a; Brabec et al., 2012; Cirisan et al., 2013). Sedimentation of ice and NAT particles is realized by allowing particles to sediment within the advected column from one box to the next lower one. For the present study the column consists of a stack of $100 \mathrm{~m}$ thick boxes and the timestep for sedimentation is $15 \mathrm{~min}$. Once ice or NAT particles grow to sizes large enough to sediment, the appropriate fraction of particles is removed from its current box and, according to its size-dependent sedimentation speed, injected into the next lower box. Sedimented particles are distributed equally over the entire box. Number and mass of the particles are conserved.

The optical properties of the simulated PSCs are calculated using Mie and T-Matrix scattering codes (Mishchenko et al., 2010) to compute optical parameters for size-resolved number densities of STS, NAT and ice. The refractive index for STS is assumed to be 1.44 (Krieger et al., 2000). For NAT, a refractive index of 1.48 was chosen, as used in several earlier studies (e.g., Carslaw et al., 1998a; Luo et al., 2003b; Fueglistaler et al., 2003). The refractive index for water ice is 1.31 (Warren, 1984). Following Engel et al. (2013), both crystals are treated as prolate spheroids with aspect ratios of 0.9 (diameter-to-length ratio). T-Matrix calculations for spheroidal NAT particles and the effect of changing aspect ratios on BSR and aerosol depolarization values are illustrated in Fig. 7 of Flentje et al. (2002). Increasing asphericity results in lower values of aerosol depolarization, which worsen the agreement between the simulations and the COBALD/CALIOP measurements.

\subsubsection{Model limitations}

The approach of using a column model has certain limitations. Strictly speaking, such an approach is only possible in situations without horizontal or vertical wind shear. Changes in wind direction or velocity with changing altitude would otherwise lead to errors in the location of the sedimentation events. The case investigated in this study is sufficiently close to meeting the criteria of a homogeneous wind field within a time window of $12 \mathrm{~h}$ downstream of $\mathrm{S} 1$, in which the modeled sedimentation event took place. Within the first $12 \mathrm{~h}$ downstream of $\mathrm{S} 1$, the distance between two trajectories, starting $3 \mathrm{~km}$ apart in altitude at potential temperatures of $520 \mathrm{~K}$ (cloud top) and $440 \mathrm{~K}$ (cloud base), is about $350 \mathrm{~km}$. This distance is within the area of ice PSCs with consistent cold temperatures, and as the modeled sedimentation takes place within these first $12 \mathrm{~h}$, the wind shear has only a moderate effect on the initial vertical redistribution of water. However, the results presented within this study refer to a longer continuing time period and the parcel's locations diverge with proceeding time (compare Fig. 1). While the column of air parcels rotate with the polar vortex, de- and rehydrated air masses may depart and disconnect from each other, whereas the simulated total water stays constant within the column. Only a three-dimensional modeling approach, which allows for mixing of air masses, can overcome this limitation.

\section{Observations}

The Arctic winter 2009/2010 was characterized by a weeklong period of unusually cold temperatures in the lower stratosphere. From 15 to 21 January, temperatures below $T_{\text {frost }}$ led to widespread synoptic-scale ice PSCs, which were observed by CALIOP (Pitts et al., 2011). The balloon sonde S1 equipped with COBALD and FLASH-B (besides ozone, meteorological parameters and GPS) was launched from Sodanklyä on 17 January 2010 at 19:47 UTC (Khaykin et al., 2013). At about 21:00 UTC the balloon reached its point of burst and the payload began its descent. COBALD and FLASH-B profiles measured during the descent are shown in Figs. 3 and 4, respectively. Particle backscatter ratios and the simultaneously captured reduction in water vapor reveal three distinct layers of ice particles. Maximum backscatter ratios at $870 \mathrm{~nm}$ reach 200 at a potential temperature of $510 \mathrm{~K}$ and mark the clearly defined upper edge of the lowest ice layer. The ice layers are embedded in a cloud of STS droplets extending from $440 \mathrm{~K}$ upwards and identified by the backscatter increase from the background level below. Above the tropopause at around $310 \mathrm{~K}$ (not shown), the Junge layer causes an elevated background level, clearly visible in the COBALD profiles at $870 \mathrm{~nm}$ in Figs. $3 \mathrm{~b}$ and e.

A vortex-wide change in PSC composition occurred on 22 January together with the onset of a major warming, and CALIOP measurements after this time showed predominantly liquid PSCs (Pitts et al., 2011). An unprecedented measurement of vertical redistribution of water followed on 23 January 2010. Sonde S2 with COBALD and CFH was launched at 17:30 UTC (Khaykin et al., 2013). A stratospheric layer of irreversibly dehydrated air was measured at potential temperatures above $470 \mathrm{~K}$. The reduction in water vapor of $1.6 \mathrm{ppmv}$ was observed in essentially ice-cloud-free air with backscatter ratios below 5 at $870 \mathrm{~nm}$. Even though temperatures at this level were as cold as on the 17 January, no ice cloud formed due to the reduced amount of $\mathrm{H}_{2} \mathrm{O}$ and hence a depression of $T_{\text {frost }}$. A clear signal of rehydration was detected below this layer (between $450 \mathrm{~K}$ and $470 \mathrm{~K}$ ). The enhancement in water vapor of about $1 \mathrm{ppmv}$ above climatological mean conditions coincided with COBALD backscatter measurements of up to 20. Backscatter values from CALIOP (between 2 and 4 at $532 \mathrm{~nm}$ ) suggest liquid particles, and enhancements of 10 to $20 \%$ in $\delta_{\text {aerosol indicate }}$ the existence of NAT particles in this layer.

\section{Microphysical analysis}

To analyze differences in PSC properties resulting from homogeneous or heterogeneous ice nucleation as well as from changes in temperatures and cooling rates, we 

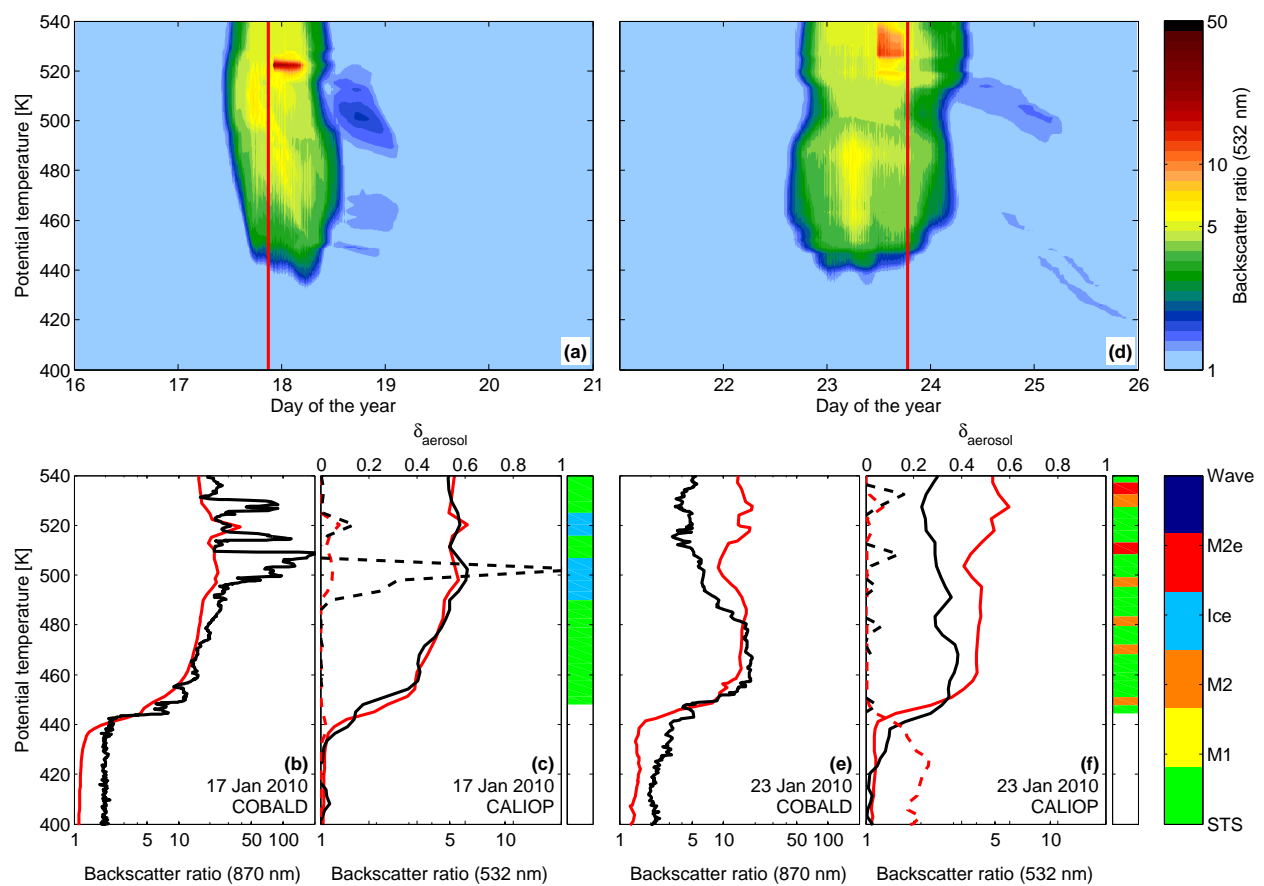

Fig. 3. Results from the microphysical column model ZOMM driven by ERA-Interim based CLaMS trajectories with superimposed smallscale temperature fluctuations. Upper panels $(\mathbf{a}, \mathbf{d})$ : time series of backscatter ratios (BSR) at $532 \mathrm{~nm}$ (color coded); vertical red lines: $\mathrm{S} 1$ and S2. Lower panels: comparison between simulations (red) and measurements (black), namely COBALD BSR at $870 \mathrm{~nm}$ (b, e) and CALIOP BSR (solid) and depolarization (dashed) at $532 \mathrm{~nm}$ (c, f). Simulations (red lines) in (c) and (f) have been interpolated corresponding to the vertical resolution of the instrument. Color bars: PSC classification scheme according to Pitts et al. (2011) for CALIOP observations. CALIOP data are from orbits 2010-01-18T00-19-57Z (c) and 2010-01-24T01-22-07Z (f) closest to Sodankylä.

performed various simulations with different initial conditions and model configurations. The results with the best agreement between simulated and observed PSC properties are shown in Figs. 3 and 4. This simulation accounted for homogeneous ice nucleation, heterogeneous nucleation of NAT and ice on foreign nuclei as well as the nucleation of ice on preexisting NAT particles and the nucleation of NAT on preexisting ice particles. Small-scale temperature fluctuations, as described in Sect. 2.3.1, needed to be superimposed onto the trajectories in order to reproduce the observations.

\subsection{Direct measurement-model comparison}

The comparison of measured and simulated optical properties, namely BSR and $\delta_{\text {aerosol }}$, is presented in Fig. 3. Here, the modeled temporal evolution of BSR at $532 \mathrm{~nm}$ along the trajectories is shown in panels a and $\mathrm{d}$ as a function of potential temperature. Figure 4 presents the corresponding results for water vapor. We started trajectories backward and forward in time as described in Sect. 2.3 along the descent of S1 (FLASH-B and COBALD) and the ascent of S2 (CFH and COBALD). The operation schedule of FLASH$\mathrm{B}$ and $\mathrm{CFH}$ and a discussion about the data quality during ascent and descent can be found in our companion paper (Khaykin et al., 2013). The simulated vertical profiles have been compared to balloon- and satellite-borne measurements. Their approximate observation time is indicated by vertical red lines in the upper panels. Their exact position is equal to the position of S1 and S2 in each case. Panel b shows modeled and observed values for the initial sounding S1 on 17 January and panel e for S2, the sounding which took place on 23 January 2010. Panels $c$ and $f$ show satellite measurements, a $25 \mathrm{~km}$ mean around the profile closest in time and space to the corresponding balloon sounding from Sodankylä. Whereas CALIPSO and Aura were $\sim 500 \mathrm{~km}$ away from Sodankylä with a time difference of $3 \mathrm{~h}$ between the individual measurements on 17 January, measurements on the 23 January have a horizontal displacement of only $\sim 100 \mathrm{~km}$ but a $6 \mathrm{~h}$ time lag. All measurements are shown in black, simulations in red. The simulated profiles in panels $\mathrm{c}$ and $\mathrm{f}$ are interpolated to the corresponding grid of CALIOP and MLS and smoothed with a moving average filter spanning $3.1 \mathrm{~km}$ for the comparison with MLS.

Simulated NAT and ice number densities as well as their mean radii are presented in Fig. 5, which shows various scenarios with respect to nucleation mechanisms and will be explained in detail below. (The rightmost column of Fig. 5 depicts the scenario from which Figs. 3 and 4 were derived.)

Temperatures above the existence temperature of NAT $\left(T_{\mathrm{NAT}}\right)$ ensure sub-saturated conditions (i.e., no PSCs) at the 

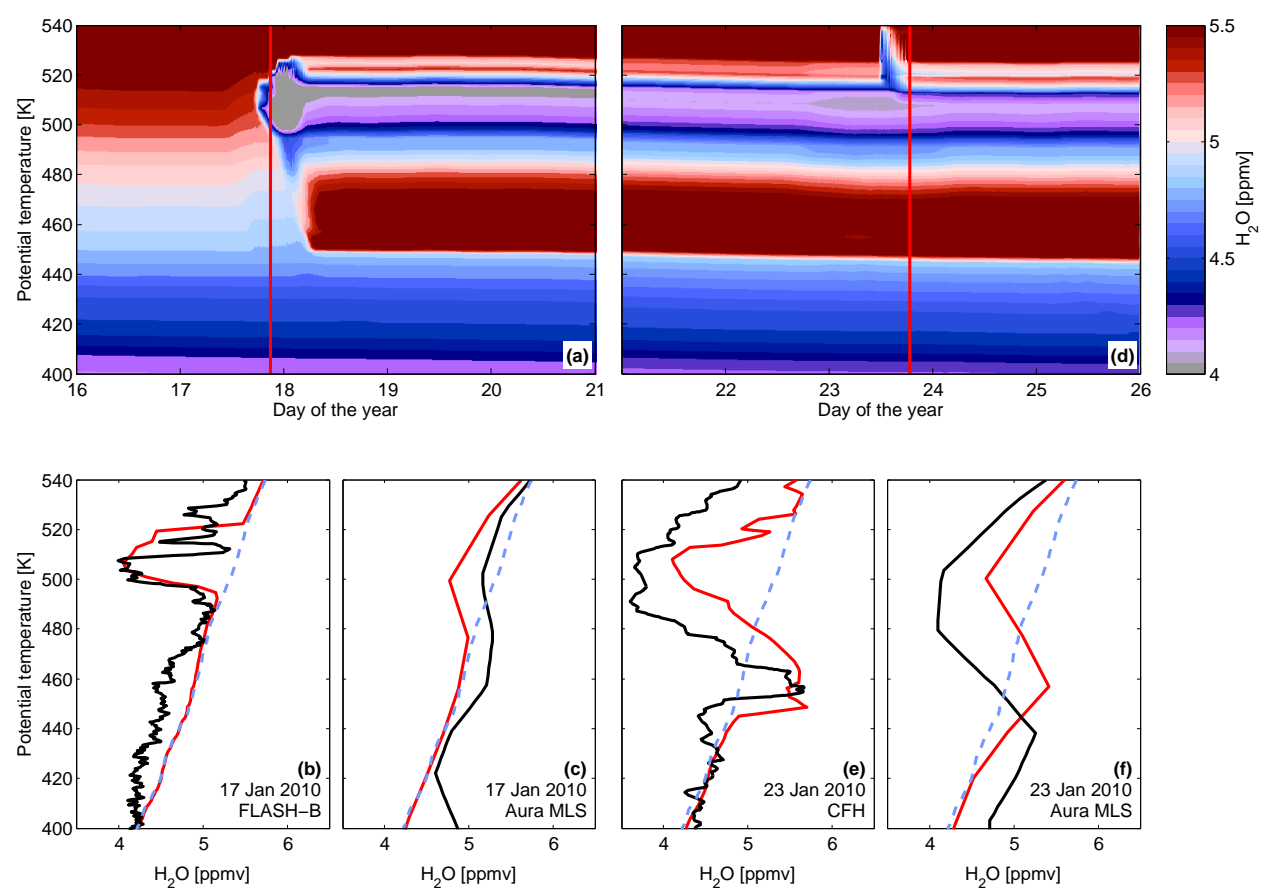

Fig. 4. Results from the microphysical column model ZOMM driven by ERA-Interim based CLaMS trajectories with superimposed smallscale temperature fluctuations. Upper panels (a, d): time series of water vapor mixing ratios (color coded); vertical red lines: S1 and S2. Lower panels: comparison between simulations (red) and measurements (black), namely FLASH-B (b), CFH (e) and MLS (c, f). Simulations (red lines) in (c) and (f) have been smoothed and interpolated corresponding to the vertical resolution of the instrument. Blue dashed line in lower panels $(\mathbf{b}, \mathbf{c}, \mathbf{e}, \mathbf{f})$ : climatological mean water vapor profile. MLS data are interpolated to orbits 2010-01-18T00-19-57Z (c) and 2010-01-24T01-22-07Z (f) closest to Sodankylä.

beginning of the simulation. Within the first $48 \mathrm{~h}$ after the start of the simulation, a significant enhancement in BSR indicates the formation of a cloud. At $t \sim 17.5$ days, temperatures become low enough to permit first NAT nucleation on preexisting particle surfaces. NAT number densities of $10^{-3} \mathrm{~cm}^{-3}$ lead to a small but visible increase in BSR. With decreasing temperatures, STS particles grow through uptake of $\mathrm{H}_{2} \mathrm{O}$ (as shown by the slightly decreasing water vapor mixing ratios in Fig. 4) and $\mathrm{HNO}_{3}$ (Fig. 7) from the gas phase and contribute significantly to a continuous increase of BSR. The onset of clearly reduced water vapor mixing ratios shortly before the point of observation is shown in Fig. 4 and marks the formation of ice particles. The comparison between simulated vertical backscatter profiles (red) with those measured by COBALD (black line in Fig. 3b) shows a reasonable agreement. However, small-scale structures of enhanced BSR seen by COBALD are only partly reflected and BSR values stay below the maximum detected by COBALD. BSR values as large as 200 (at $870 \mathrm{~nm}$ ) may be simulated by choosing a slightly different phase of a fluctuation as seen in the presentation of the ensemble runs below. As Fig. 3c shows, CALIOP measurements (black line) are represented extremely well. Simulated $\delta_{\text {aerosol values are }}$ enhanced in the same altitude region as in the CALIOP observations, but values of $\delta_{\text {aerosol }}$ measured by CALIOP fluc- tuate more strongly, producing "jumps" between the ice and STS class (compare dashed lines in Fig. 3c). Even though instrumental noise and the lower resolution might be an explanation for this behavior, COBALD measures large fluctuations in BSR, which suggests changes in the underlying cloud composition, too. A profound anti-correlation between the profiles of BSR and $\mathrm{H}_{2} \mathrm{O}$ (black lines in Fig. 3b and Fig. $4 \mathrm{~b}$, respectively) strengthens the reliability of the two independent measurements. Enhancements in BSR and a corresponding depletion in the vapor phase, both strongly layered, suggests an ice cloud. The small color bar next to the vertical profiles denotes the results from the CALIOP particle classification scheme and supports the existence of distinct layers of ice embedded in a broader liquid PSC. A detailed discussion of the BSR and water vapor measurements together with a presentation of both within the same plot can be found in Khaykin et al. (2013). Simulated ice number densities in the core of the cloud lie between $10^{-3} \mathrm{~cm}^{-3}$ and $10^{-2} \mathrm{~cm}^{-3}$, leading to a maximum BSR at $532 \mathrm{~nm}$ of almost 7. In Fig. 3a, downwind of S1, homogeneous ice nucleation sets in and higher ice number densities between $0.1 \mathrm{~cm}^{-3}$ and $1 \mathrm{~cm}^{-3}$ are simulated. Those high number densities cause an increase in BSR by a factor of 3.5. The part of the ice cloud with the highest BSR values is followed by a tail of moderate BSR upon warming, whereas elsewhere BSR values are 

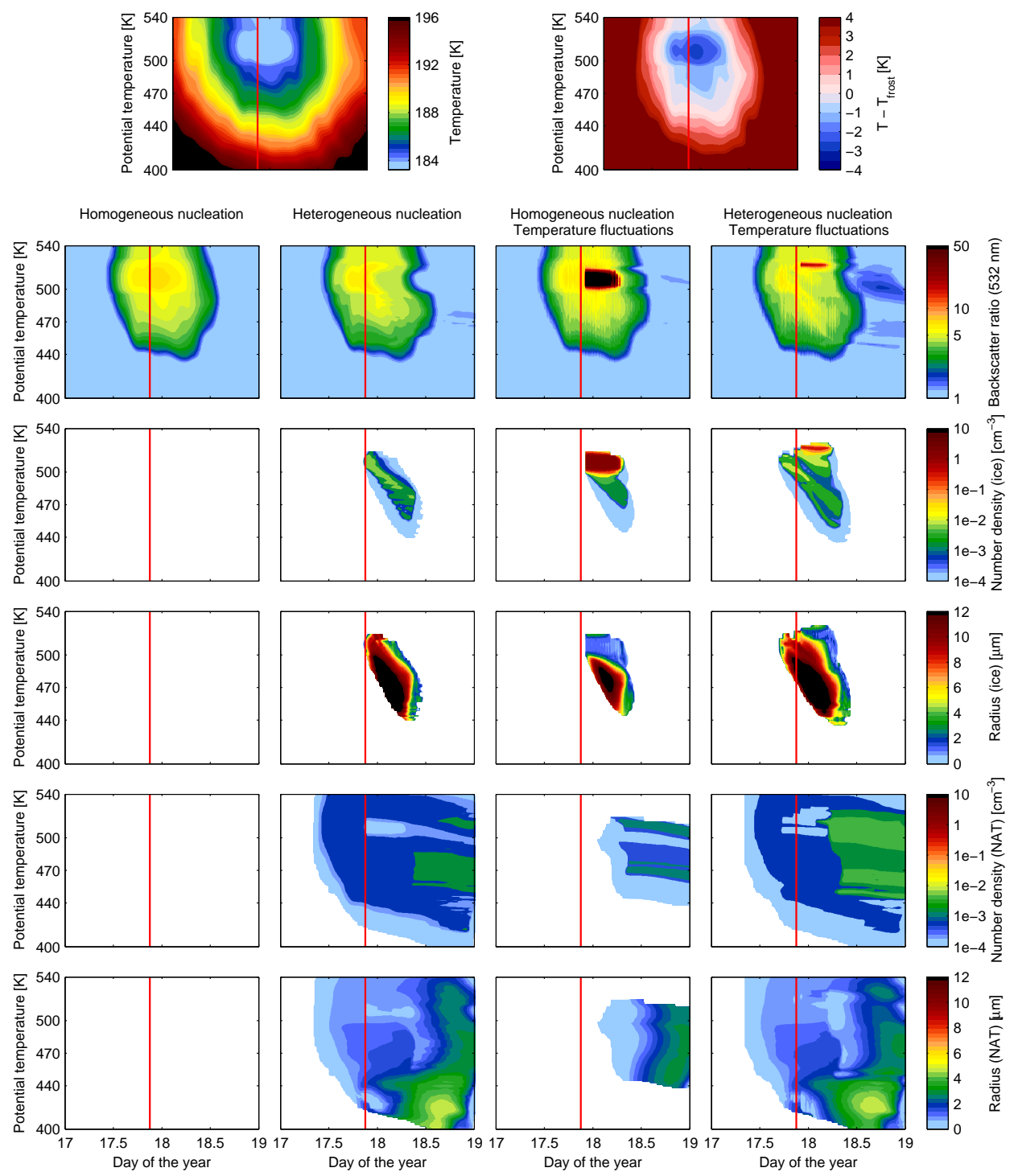

Fig. 5. Results from the microphysical column model ZOMM driven by ERA-Interim based CLaMS trajectories (17-19 January 2010). Vertical red line: S1. Top panels: ERA-Interim temperatures (temperature correction applied) shown as absolute temperature (left panel) and relative to the frost point temperature $\left(T_{\text {frost }}\right)$, which has been calculated from the climatological mean water vapor profile (right panel). Rows: backscatter ratios at $532 \mathrm{~nm}$, ice and NAT number densities and radii. Columns show four different scenarios: column 1 - only homogeneous nucleation of ice, no superimposed temperature fluctuations; column 2 - same, but in addition allow for heterogeneous nucleation; column 3 - only homogeneous nucleation of ice, but with superimposed small-scale temperature fluctuations; column 4 - with both, heterogeneous nucleation and superimposed temperature fluctuations. Homogeneous simulations include homogeneous ice nucleation and NAT nucleation on preexisting ice particles only. Heterogeneous model runs also include heterogeneous ice and NAT nucleation on foreign nuclei.

much smaller. This tail consists of NAT particles (see Fig. 5) that nucleated on the ice cloud, forming a NAT cloud of class "Mix2" and "Mix2-enh", as first described by Carslaw et al. (1998a).

The magnitude of the $\mathrm{H}_{2} \mathrm{O}$ reduction in the gas phase observed by FLASH-B is roughly captured by the simulations. Again, fine-scale structures are not reproduced by the model (Fig. 4b). The resolution of MLS is too coarse to capture the local reduction in $\mathrm{H}_{2} \mathrm{O}$ at this time (Fig. 4c). Ice particles evaporate already $12 \mathrm{~h}$ after the FLASH-B observation and a clear and permanent redistribution of $\mathrm{H}_{2} \mathrm{O}$ becomes visible at $t \sim 18.5$ days in Fig. 4a, and it remains visible until the end of the simulation.

Close to the second observation, temperatures drop again and reach values almost as cold as on the 17 January. However, the reduction in $\mathrm{H}_{2} \mathrm{O}$ prevents the formation of ice clouds in the model, except at levels above $520 \mathrm{~K}$. Also the magnitude of BSR from COBALD (20 at $870 \mathrm{~nm}$ ) and 
CALIOP ( 3 at $532 \mathrm{~nm}$ ) would not suggest an ice cloud. Values of BSR remain smaller than they were on 17 January and CALIOP observations suggest a predominantly liquid cloud with few embedded NAT particles. The NAT signal is partially obscured by the strong STS signal (Fig. 3f). The comparison between modeled and observed $\mathrm{H}_{2} \mathrm{O}$ reveals that even though the model captures signatures of de- and rehydration, the vertical extent of the dehydrated air remains too small in the simulation. The simulated maximum reduction in water vapor of $1.4 \mathrm{ppm}$ at $514 \mathrm{~K}$ is almost as large as observed by CFH. However, the dehydrated region is smaller in vertical extent and ranges only from $485 \mathrm{~K}$ to $525 \mathrm{~K}$. A possible explanation of the underestimated vertical extent of dehydrated air in the simulation might again be the temperature profile. Figure $2 \mathrm{~b}$ shows that ERA-Interim temperatures are also too warm compared to the observation at the top of the sounding, which prevents the formation of ice particles above $525 \mathrm{~K}$. The resulting availability of $\mathrm{H}_{2} \mathrm{O}$ at high altitudes offers the possibility for ice formation on the 23 January 2010 in our simulation, whereas CALIOP observations documented the last ice clouds in the vortex on 21 January (Pitts et al., 2011).

Whereas ZOMM underestimates the vertical extent of the dehydrated air, it overestimates the dimension of the rehydrated signature. This is related to uncertainties of the $\mathrm{H}_{2} \mathrm{O}$ profile used to initialize the model and/or to wind shear (horizontal shear is unimportant due to the constraint of the rotating air in the vortex, but vertical shear is significant). The column model is rigorously mass-conserving. However, independent of temperatures and the nucleation mechanism, ZOMM cannot simultaneously reproduce both, the de- and rehydration signatures observed by $\mathrm{CFH}$ relative to the assumed initial $\mathrm{H}_{2} \mathrm{O}$ profile. Inspection of Fig. 2 of Khaykin et al. (2013) reveals the day-to-day variability between the individual water vapor profiles. Whereas the agreement between the measurement and the mean values is almost perfect in undisturbed air masses below $450 \mathrm{~K}$ on 22 January 2010 , there is variability on 17 and 23 January 2010. A different initial profile on these days could be consistent with massbalanced profiles in the observations. Nevertheless, such profiles remain speculative and we refrained from changing the initial profile for model improvement, while the observed profiles could be affected by wind shear. A three-dimensional treatment of the wind fields, which also includes wind shear and mixing of air masses, would be required (but with such a model, additional uncertainties would be introduced and the detailed microphysics could hardly be tested). These issues hardly impact the results for S1 during the short (2-day) runup of the model, whereas they clearly affect $S 2$. Nevertheless, the different scenarios discussed in the subsequent paragraph and presented in Fig. 5 and Fig. 6 are robust and allow clear conclusions.

Figure 5 compares simulations using four different scenarios. The top panels show ERA-Interim temperatures, which were corrected according to the measured temperature pro- file of S1 (compare Sect. 2.3 and Fig. 2) and provide the basis for all four simulations. The simulated profiles at $\mathrm{S} 1$ and S2 can be seen for each scenario in Fig. 6 together with the observations. Figure 6 will be explained and discussed in detail in Sect. 4.2. The first scenario (Fig. 5, 1st column), which accounts only for homogeneous ice nucleation, cannot explain the observations at all. Supersaturations with respect to ice remain too small and since no ice particles form, NAT particles cannot form either. The second scenario (Fig. 5, 2nd column), which includes heterogeneous nucleation of ice and NAT particles according to Engel et al. (2013) and Hoyle et al. (2013), changes the model results completely. Ice supersaturations are sufficient for heterogeneous nucleation of $10^{-3} \mathrm{~cm}^{-3}$ ice particles. Within a short time, these particles grow to sizes $>12 \mu \mathrm{m}$ in radius. With a settling velocity between $100 \mathrm{mh}^{-1}$ and $200 \mathrm{mh}^{-1}$, ice particles can sediment up to $2 \mathrm{~km}$ before evaporation. The third scenario (Fig. 5, 3rd column) shows that the superposition of small-scale temperature fluctuations on the synoptic trajectories leads to ice formation even in the homogeneous freezing case. However, this result does not agree with the observations, because the nucleation of high ice number densities (between $1 \mathrm{~cm}^{-3}$ and $10 \mathrm{~cm}^{-3}$ ) prevents the growth of ice particles to sizes which could sediment fast enough to achieve a satisfying agreement with the water vapor observations (maximum sedimentation distances of only a few hundred meters). The final scenario (Fig. 5, 4th column) includes both heterogeneous nucleation and superimposed small-scale temperature fluctuations. The inclusion of heterogeneous nucleation in this simulation causes NAT to form prior to ice. Consequently, those NAT particles are assumed to be enclosed by ice and redistributed by the subsequent growth and sedimentation of the ice particles. We will discuss this point further below. Additionally, the nucleation of ice particles starts earlier than in all other cases and the fluctuations enable a larger ice cloud area to be generated.

\subsection{Ensemble calculations for stochastic impact of temperature fluctuations}

Figures 3-5 show the comparison between the measurements and the ZOMM calculations for one particular set of smallscale temperature fluctuations. The properties of the NAT and ice clouds depend on the exact cooling rates at the moment of the nucleation of the NAT and ice particles, because this dictates the nucleation rates. This happens at the place of cloud formation somewhere upstream of the measurements and is, in principle, unknown to us. At best we have an idea of the statistical nature of the small-scale temperature fluctuations, which determine the cooling rates and thus the resulting cloud morphology. Therefore, ensemble calculations applying different sets of small-scale temperature fluctuations need to be performed in order to retrieve the dependence of PSC properties on the stochastic effects caused by 

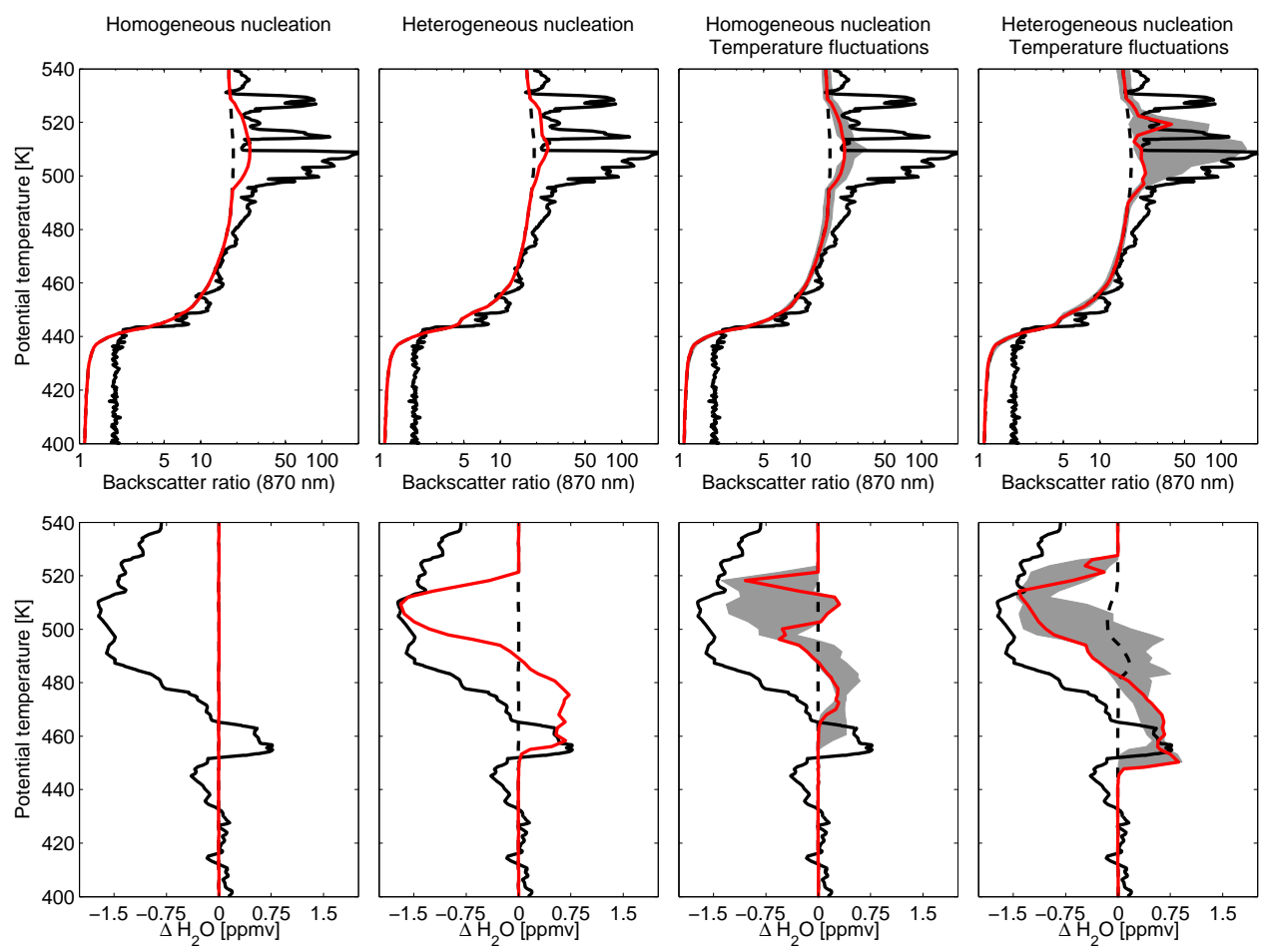

Fig. 6. Comparison between measured and simulated profiles of backscatter ratios (BSR) for S1 (upper row) and water vapor mixing ratios for S2 (lower row). Mixing ratios are expressed as deviation from the climatological mean water vapor profile. The four different model scenarios are the same as in Fig. 5. Black line: COBALD (upper row) and CFH (lower row) measurements. Gray shaded area: variations caused by different small-scale temperature fluctuations modeled by an ensemble with 10 members. Red line: model results for the best fluctuation member shown in Figs. 3-5. Dashed line: model results obtained without temperature correction (as shown in Fig. 2).

the fluctuations. Cirisan et al. (2013) have performed similar calculations for cirrus clouds.

Figure 6 presents a comparison of profiles of BSR and $\Delta \mathrm{H}_{2} \mathrm{O}$ for various scenarios with and without heterogeneous nucleation and with 10 different sets of small-scale temperature fluctuations. BSR profiles for 17 January are presented in the upper four panels, $\Delta \mathrm{H}_{2} \mathrm{O}$ profiles for 23 January are shown in the lower four panels. The model results, which have already been described above and shown in Figs. 3-5, correspond to the red curves while the other nine members are shown as gray shaded areas. The red curves also represent the particular member which produced the best agreement with the measurements in terms of dehydration.

As expected, no signatures of de- or rehydration are visible if only homogeneous ice nucleation and synoptic-scale temperatures are applied. The lower row shows that an improved agreement between $\mathrm{CFH}$ and the simulation can only be achieved if heterogeneous ice nucleation or small-scale temperature fluctuations are included, or both. However, when heterogeneous nucleation is included but not the small-scale temperature fluctuations (2nd column), modeled values of BSR remain too small in comparison with COBALD BSR values. Conversely, combining homogeneous nucleation and the superposition of small-scale temperature fluctuations improves the modeled backscatter, but generates an irregular signature of two layers of dehydration (red curve in 3rd column). Taken together, heterogeneous ice nucleation and superimposed small-scale temperature fluctuations combine the improvement in terms of BSR values with clear signatures of de- and rehydration, which agree well with the measurements (red curve in 4th column). Particular choices of fluctuations can generate BSR values as large as the spikes observed by COBALD during sounding S1. This demonstrates that different fluctuations generate different ice number densities, and this in turn leads to different backscatter ratios and dehydration strengths. In passing we note that the spikes in BSR observed during S1 represent onsets of wave ice embedded in a synoptic ice cloud. The spikes contain ice crystals in high number density, which cannot grow to large sizes and thus cannot explain the vertical redistribution of water observed about a week later. Therefore, those ensemble members which represent the highest BSR measurements best lead only to shallow dehydration. Rather, it is the synoptic-scale ice with moderate ice number concentrations and therefore moderate BSR values which cause the most efficient dehydration. This is reflected in the CALIOP measurements. Vortex wide, $65 \%$ of the CALIOP measurements, which have been classified as ice according to Pitts et al. (2011), have BSRs smaller than 10. BSRs of less than 20 have been observed in $89 \%$ of the data collected on 17 
and 18 January 2010. However, a certain scatter of BSRs still exists, possibly originating from temperature perturbations, much like what is seen in the model results when a range of temperature fluctuations is used.

Finally, to demonstrate the need for the temperature correction depicted in Fig. $2 \mathrm{~b}$ and $\mathrm{c}$, we included, as dashed black lines in Fig. 6, model results based on the original ERA-Interim trajectories with and without superimposed small-scale temperature fluctuations. The only simulation which produced any dehydration signal is the one combining heterogeneous nucleation with temperature fluctuations. However, the modeled dehydration is much smaller than that observed.

\subsection{Relevance for denitrification}

Denitrification plays an important role in ozone loss by slowing the conversion of chlorine radicals back into reservoir species. This process may cause an enhancement of ozone destruction and can lead to increased accumulated ozone losses over the course of the winter (e.g., Müller et al., 1994). Denitrification is particularly important in the Arctic with its warmer temperatures (e.g., Chipperfield and Pyle, 1998) and severe denitrification has been a major factor in bringing about the record ozone loss in the Arctic winter 2010/2011 (Manney et al., 2011; Pommereau et al., 2013).

Recent observations suggest the possibility of heterogeneous ice nucleation on preexisting NAT particles. Pitts et al. (2011) observed an increase in synoptic-scale ice PSCs concomitant with decreasing number densities of NAT mixtures in January 2010. Such a process would imply that the sedimentation of ice particles not only dehydrates but also denitrifies the stratosphere due to the removal of $\mathrm{HNO}_{3}$. Khosrawi et al. (2011) investigated this hypothesis and offered ice nucleation on NAT particles as a possible explanation for the low $\mathrm{HNO}_{3}$ observations by the Sub-Millimetre Radiometer (SMR) aboard the Odin satellite and Aura/MLS during the same winter. However, the present modeling study reveals that dehydration and denitrification are not necessarily related to each other. The observed case does not significantly contribute to the overall denitrification for the following reasons. At the start of the simulations, before ice formation, the nucleation of NAT on foreign nuclei accounts for NAT number densities of $10^{-3} \mathrm{~cm}^{-3}$, but the effective radius of NAT particles formed along the trajectories does not exceed $2 \mu \mathrm{m}$. The amount of $\mathrm{HNO}_{3}$ condensing on these NAT particles is negligible, namely less than $10 \%$ of the total available $\mathrm{HNO}_{3}$, while the major fraction of $\mathrm{HNO}_{3}$ resides in the liquid droplets. This results in a depletion in the gas phase $\mathrm{HNO}_{3}$ (see denoxification in Fig. 7a) and decelerates the growth of the NAT particles (see Fig. 4 in Voigt et al., 2005). Next, ice nucleates, partly on the preexisting NAT, and $\mathrm{HNO}_{3}$ also co-condenses on the growing ice particles, which sediment and dehydrate efficiently. However, the resulting denitrification is minor, as most of the mass of the falling particles is composed of water molecules. After the ice has evaporated, NAT particles are released and would have the chance to denitrifiy the air, if they could survive long enough to grow. However, the air warms rapidly from $T<T_{\text {frost }}$ to $T>T_{\mathrm{NAT}}$ (see Fig. 1) and does not stay in the interval $T_{\mathrm{NAT}}-5 \mathrm{~K}<T<T_{\mathrm{NAT}}-2 \mathrm{~K}$, which is most efficient for denitrification (Voigt et al., 2005), for a sufficient amount of time. The resulting denitrification signal in Fig. $7 \mathrm{~b}$ shows redistributions of $\mathrm{HNO}_{3}$ over small height differences, but no strong, coherent denitrification. This impression is independent of the nucleation scenario or the phase of the temperature fluctuation and, thus, very robust. Instead, the strong denitrification of the Arctic winter 2009/2010 occurred during the first half of January, that is, before the onset of synoptic-scale ice clouds, and was likely caused by NAT clouds downwind of mountain wave ice PSCs, which can act as mother clouds for so-called NAT rocks (Fueglistaler et al., 2002). Evidence of this can be seen in the Odin/SMR and Aura/MLS satellite measurements of $\mathrm{HNO}_{3}$ shown in Fig. 3 of Khosrawi et al. (2011). In the beginning of January 2010, gas phase mixing ratios of $\mathrm{HNO}_{3}$ decreased significantly at high altitudes and remained low until the end of February. Below $50 \mathrm{hPa}$, a concurrent $\mathrm{HNO}_{3}$ increase is visible in the data, which allows the conclusion that a permanent, vertical redistribution of $\mathrm{HNO}_{3}$ may have taken place. Minimum values of gas phase $\mathrm{HNO}_{3}$ were observed by Aura/MLS in the second half of January at the same time than CALIOP confirmed the existence of synoptic-scale ice clouds. However, the renitrified layer below showed no further increase in $\mathrm{HNO}_{3}$. Instead, $\mathrm{HNO}_{3}$ mixing ratios above $50 \mathrm{hPa}$ increased again with proceeding time and increasing temperatures. Hence, we expect denoxification and no additional deand renitrification at this time in the winter. Recent CLaMS simulations show a similar picture with $\mathrm{HNO}_{3}$ fluxes largest in the first half of January (Grooß et al., 2014). For this reason, we cannot confirm the suggestion by Khosrawi et al. (2011), namely that the observed denitrification was linked to ice particle formation on NAT during the synoptic cooling event in mid-January. This case study indicates that the conditions that led to the observed dehydration in the second half of January 2010 would not support sufficient growth of NAT particles to lead to significant denitrification.

\section{Discussion and conclusions}

Unprecedented de- and rehydration was observed above Sodankylä during the Arctic winter 2009/2010. Using a microphysical column model, we were able to relate two unique balloon soundings by means of trajectories, one showing the redistribution of water from the gas phase into the ice phase without sedimentation, the second six days later showing the effects of gravitational settling and irreversible dehydration. To corroborate this interpretation we simulated the formation and sedimentation of the ice particles. Simulated water vapor 


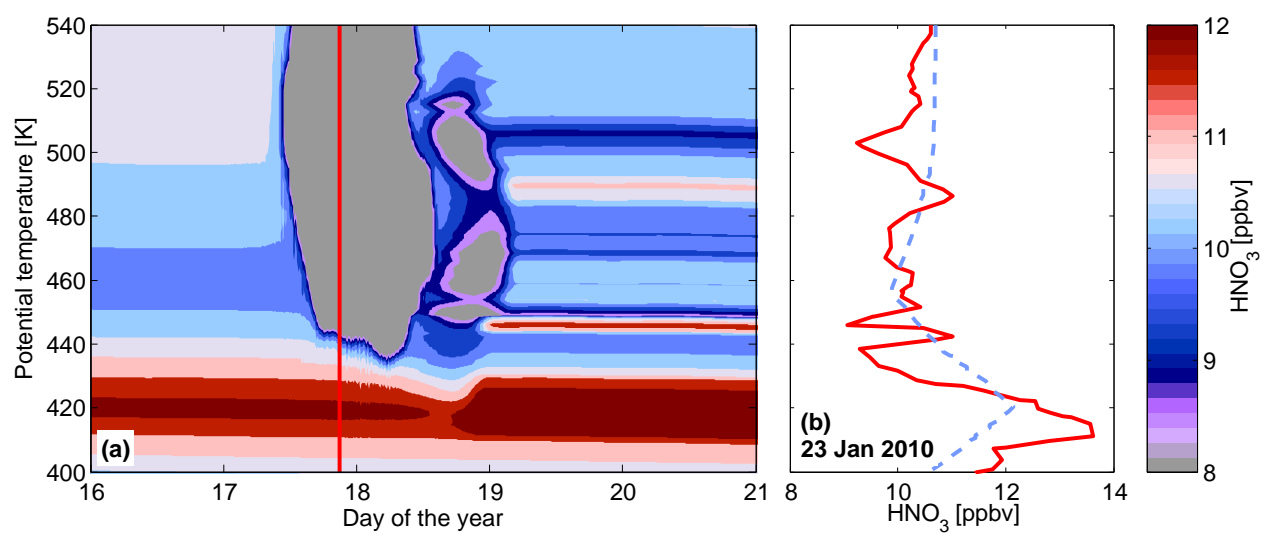

Fig. 7. Results from the microphysical column model ZOMM driven by ERA-Interim based CLaMS trajectories with superimposed smallscale temperature fluctuations. (a) Time series of gas phase nitric acid mixing ratios (color coded); vertical red line: S1. (b) Simulated total nitric acid profile (red) at S2 compared to the initial nitric acid profile (blue dashed).

profiles agree reasonably with CFH and FLASH-B carried by the balloon sondes and with MLS satellite measurements. Optical T-Matrix calculations enabled the direct comparison of the simulations with COBALD and CALIOP backscatter measurements. To this end, we examined the effect of smallscale temperature fluctuations and compared homogeneous vs. heterogeneous formation of ice particles.

It was demonstrated that heterogeneous nucleation of ice is essential to reproduce the observed de- and rehydration signatures. Even though ERA-Interim temperatures along the trajectories had to be lowered by up to $1.5 \mathrm{~K}$ in order to obtain agreement with the temperatures measured by the sondes, temperatures stayed above $T_{\text {frost }}-3 \mathrm{~K}$, which is the temperature required for homogeneous nucleation of ice in ternary solution droplets. Small-scale temperature fluctuations additionally lowered the temperature, caused higher supersaturations and therefore enabled the formation of ice clouds, even when homogeneous ice nucleation was the only allowed ice formation pathway. However, homogeneous nucleation at high supersaturations resulted in ice formation with the characteristics of wave clouds: high number densities of particles remain too small to sediment and cannot explain the observed vertical redistribution of water. In contrast, heterogeneous ice nucleation takes place at lower supersaturations, causing a selective freezing of only a few ice crystals. Those particles can grow to sizes large enough $(r \gtrsim 10 \mu \mathrm{m})$ to settle fast and reproduce the signatures of de- and rehydration.

Even though small-scale temperature fluctuations are not required to achieve de- and renitrification in the present case, the resulting PSC backscatter is too low without smallscale temperature fluctuations, and rapid cooling rates help to improve the agreement with the COBALD measurements. However, the two balloon soundings provide only snapshots of the atmosphere, which depend on the precise temperature variations not only at the point of observation, but also upstream along the air parcel trajectories. Discrepancies be- tween ERA-Interim temperature fields and measured temperatures were found, which we needed to correct. Whereas Sodankylä, located at the edge of the cold pool, is characterized by temperatures just below $T_{\text {frost }}$ and is therefore very sensitive to the smallest of temperature changes, the CALIOP measurements show large areas deeper in the vortex with persistent synoptic-scale ice clouds. The observed dehydration above Sodankylä, not only on 23 January but also a few days earlier and later (as shown by Khaykin et al., 2013), is most likely caused by such large-scale fields of persistent ice clouds and not by the observed small-scale structures above Sodankylä. The fact that the reduction in $\mathrm{H}_{2} \mathrm{O}$ measured by $\mathrm{CFH}$ is not balanced by the rehydration layer below suggests that wind shear and subsequent mixing of air masses have affected the observed profile. An accurate estimate of these effects can only be made using a three-dimensional modeling approach.

Acknowledgements. This work was supported by the European Commission Seventh Framework Programme (FP7) under the grant number RECONCILE-226365-FP7-ENV-2008-1. Support for C. R. Hoyle was obtained from the Swiss National Science Foundation (SNSF) under the grant numbers 200021_120175/1 (Modelling Heterogeneous and Homogeneous Ice Nucleation and Growth at Cirrus Cloud Levels) and 200021_140663 (Modelling of aerosol effects in mixed-phase clouds). Partial support for S. M. Khaykin received by the Russian Foundation for Basic Research (grant numbers 12-05-31384 and 11-05-00475). Water vapor and aerosol soundings in Sodankylä were partially supported by the Finnish Academy under grant number 140408. Aura MLS gas species data were provided courtesy of the MLS team and obtained through the Aura MLS website (http://mls.jpl.nasa.gov/index-eos-mls.php). Particular gratitude to Alexey Lykov (CAO) who carried out FLASH-B flight on 17 January 2010.

Edited by: F. Khosrawi 


\section{References}

Brabec, M., Wienhold, F. G., Luo, B. P., Vömel, H., Immler, F., Steiner, P., Hausammann, E., Weers, U., and Peter, T.: Particle backscatter and relative humidity measured across cirrus clouds and comparison with microphysical cirrus modelling, Atmos. Chem. Phys., 12, 9135-9148, doi:10.5194/acp-12-9135-2012, 2012.

Bukowiecki, N., Zieger, P., Weingartner, E., Jurányi, Z., Gysel, M., Neininger, B., Schneider, B., Hueglin, C., Ulrich, A., Wichser, A., Henne, S., Brunner, D., Kaegi, R., Schwikowski, M., Tobler, L., Wienhold, F. G., Engel, I., Buchmann, B., Peter, T., and Baltensperger, U.: Ground-based and airborne in-situ measurements of the Eyjafjallajökull volcanic aerosol plume in Switzerland in spring 2010, Atmos. Chem. Phys., 11, 10011-10030, doi:10.5194/acp-11-10011-2011, 2011.

Carslaw, K. S., Wirth, M., Tsias, A., Luo, B. P., Dörnbrack, A., Leutbecher, M., Volkert, H., Renger, W., Bacmeister, J. T., and Peter, T.: Particle microphysics and chemistry in remotely observed mountain polar stratospheric clouds, J. Geophys. Res., 103, 5785-5796, doi:10.1029/97JD03626, 1998a.

Carslaw, K. S., Wirth, M., Tsias, A., Luo, B. P., Dörnbrack, A., Leutbecher, M., Volkert, H., Renger, W., Bacmeister, J. T., Reimer, E., and Peter, T.: Increased stratospheric ozone depletion due to mountain-induced atmospheric waves, Nature, 391, 675-678, doi:10.1038/35589, 1998b.

Chipperfield, M. P. and Pyle, J. A.: Model sensitivity studies of Arctic ozone depletion, J. Geophys. Res., 103, 28389-28403, doi:10.1029/98JD01960, 1998.

Cirisan, A., Luo, B. P., Engel, I., Wienhold, F. G., Krieger, U. K., Weers, U., Romanens, G., Levrat, G., Jeannet, P., Ruffieux, D., Philipona, R., Calpini, B., Spichtinger, P., and Peter, T.: Balloonborne match measurements of mid-latitude cirrus clouds, Atmos. Chem. Phys. Discuss., 13, 25417-25479, doi:10.5194/acpd-1325417-2013, 2013.

Dee, D. P., Uppala, S. M., Simmons, A. J., Berrisford, P., Poli, P., Kobayashi, S., Andrae, U., Balmaseda, M. A., Balsamo, G., Bauer, P., Bechtold, P., Beljaars, A. C. M., van de Berg, L., Bidlot, J., Bormann, N., Delsol, C., Dragani, R., Fuentes, M., Geer, A. J., Haimberger, L., Healy, S. B., Hersbach, H., Hólm, E. V., Isaksen, L., Kållberg, P., Köhler, M., Matricardi, M., McNally, A. P., Monge-Sanz, B. M., Morcrette, J.-J., Park, B.-K., Peubey, C., de Rosnay, P., Tavolato, C., Thépaut, J.-N., and Vitart, F.: The ERA-Interim reanalysis: configuration and performance of the data assimilation system, Q. J. Roy. Meteor. Soc., 137, 553-597, doi:10.1002/qj.828, 2011.

Drdla, K., Schoeberl, M. R., and Browell, E. V.: Microphysical modeling of the 1999-2000 Arctic winter: 1. Polar stratospheric clouds, denitrification, and dehydration, J. Geophys. Res., 107, SOL 55-1-SOL 55-21, doi:10.1029/2001JD000782, 2002.

Dye, J. E., Baumgardner, D., Gandrud, B. W., Kawa, S. R., Kelly, K. K., Loewenstein, M., Ferry, G. V., Chan, K. R., and Gary, B. L.: Particle Size Distributions in Arctic Polar Stratospheric Clouds, Growth and Freezing of Sulfuric Acid Droplets, and Implications for Cloud Formation, J. Geophys. Res., 97, 80158034, doi:10.1029/91JD02740, 1992.

Engel, I., Luo, B. P., Pitts, M. C., Poole, L. R., Hoyle, C. R., Grooß, J.-U., Dörnbrack, A., and Peter, T.: Heterogeneous formation of polar stratospheric clouds - Part 2: Nucleation of ice on synoptic scales, Atmos. Chem. Phys., 13, 10769-10785, doi:10.5194/acp13-10769-2013, 2013.

Fahey, D. W., Kelly, K. K., Kawa, S. R., Tuck, A. F., Loewenstein, M., Chan, K. R., and Heidt, L. E.: Observations of denitrification and dehydration in the winter polar stratospheres, Nature, 344, 321-324, doi:10.1038/344321a0, 1990.

Flentje, H., Dörnbrack, A., Fix, A., Meister, A., Schmid, H., Fueglistaler, S., Luo, B. P., and Peter, T.: Denitrification inside the stratospheric vortex in the winter of 1999-2000 by sedimentation of large nitric acid trihydrate particles, J. Geophys. Res., 107, AAC 11-1-AAC 11-15, doi:10.1029/2001JD001015, 2002.

Fueglistaler, S., Luo, B. P., Voigt, C., Carslaw, K. S., and Peter, T.: NAT-rock formation by mother clouds: a microphysical model study, Atmos. Chem. Phys., 2, 93-98, doi:10.5194/acp-2-932002, 2002.

Fueglistaler, S., Buss, S., Luo, B. P., Wernli, H., Flentje, H., Hostetler, C. A., Poole, L. R., Carslaw, K. S., and Peter, T.: Detailed modeling of mountain wave PSCs, Atmos. Chem. Phys., 3, 697-712, doi:10.5194/acp-3-697-2003, 2003.

Gary, B. L.: Mesoscale temperature fluctuations in the stratosphere, Atmos. Chem. Phys., 6, 4577-4589, doi:10.5194/acp-6-45772006, 2006.

Grooß, J.-U., Engel, I., Borrmann, S., Frey, W., Günther, G., Hoyle, C. R., Kivi, R., Luo, B. P., Molleker, S., Peter, T., Pitts, M. C., Schlager, H., Stiller, G., Vömel, H., Walker, K. A., and Müller, R.: Nitric acid trihydrate nucleation and denitrification in the Arctic stratosphere, Atmos. Chem. Phys., 14, 1055-1073, doi:10.5194/acp-14-1055-2014, 2014.

Hoyle, C. R., Luo, B. P., and Peter, T.: The origin of high ice crystal number densities in cirrus clouds, J. Atmos. Sci., 62, 2568-2579, doi:10.1175/JAS3487.1, 2005.

Hoyle, C. R., Engel, I., Luo, B. P., Pitts, M. C., Poole, L. R., Grooß, J.-U., and Peter, T.: Heterogeneous formation of polar stratospheric clouds - Part 1: Nucleation of nitric acid trihydrate (NAT), Atmos. Chem. Phys., 13, 9577-9595, doi:10.5194/acp13-9577-2013, 2013.

Jimenez, C., Pumphrey, H. C., MacKenzie, I. A., Manney, G. L., Santee, M. L., Schwartz, M. J., Harwood, R. S., and Waters, J. W.: EOS MLS observations of dehydration in the 2004-2005 polar winters, Geophys. Res. Lett., 33, L16806, doi:10.1029/2006GL025926, 2006.

Kärcher, B. and Lohmann, U.: A parameterization of cirrus cloud formation: Heterogeneous freezing, J. Geophys. Res., 108, 4402, doi:10.1029/2002JD003220, 2003.

Kelly, K. K., Tuck, A. F., Murphy, D. M., Proffitt, M. H., Fahey, D. W., Jones, R. L., McKenna, D. S., Loewenstein, M., Podolske, J. R., Strahan, S. E., Ferry, G. V., Chan, K. R., Vedder, J. F., Gregory, G. L., Hypes, W. D., McCormick, M. P., Browell, E. V., and Heidt, L. E.: Dehydration in the lower Antarctic stratosphere during late winter and early spring, 1987, J. Geophys. Res., 94, 11317-11357, doi:10.1029/JD094iD09p11317, 1989.

Khaykin, S. M., Engel, I., Vömel, H., Formanyuk, I. M., Kivi, R., Korshunov, L. I., Krämer, M., Lykov, A. D., Meier, S., Naebert, T., Pitts, M. C., Santee, M. L., Spelten, N., Wienhold, F. G., Yushkov, V. A., and Peter, T.: Arctic stratospheric dehydration - Part 1: Unprecedented observation of vertical redistribution of water, Atmos. Chem. Phys., 13, 11 503-11 517, doi:10.5194/acp13-11503-2013, 2013. 
Khosrawi, F., Urban, J., Pitts, M. C., Voelger, P., Achtert, P., Kaphlanov, M., Santee, M. L., Manney, G. L., Murtagh, D., and Fricke, K.-H.: Denitrification and polar stratospheric cloud formation during the Arctic winter 2009/2010, Atmos. Chem. Phys., 11, 8471-8487, doi:10.5194/acp-11-8471-2011, 2011.

Kley, D. and Stone, E. J.: Measurement of water vapor in the stratosphere by photo dissociation with Ly-Alpha (1216 A) light, Rev. Sci. Instrum., 49, 691-697, doi:10.1063/1.1135596, 1978.

Koop, T., Biermann, U. M., Raber, W., Luo, B. P., Crutzen, P. J., and Peter, T.: Do stratospheric aerosol droplets freeze above the ice frost point?, Geophys. Res. Lett., 22, 917-920, doi:10.1029/95GL00814, 1995.

Koop, T., Luo, B. P., Tsias, A., and Peter, T.: Water activity as the determinant for homogeneous ice nucleation in aqueous solutions, Nature, 406, 611-614, doi:10.1038/35020537, 2000.

Krieger, U. K., Mössinger, J. C., Luo, B. P., Weers, U., and Peter, T.: Measurement of the Refractive Indices of $\mathrm{H}_{2} \mathrm{SO}_{4}-\mathrm{HNO}_{3}-\mathrm{H}_{2} \mathrm{O}$ Solutions to Stratospheric Temperatures, Appl. Opt., 39, 36913703, doi:10.1364/AO.39.003691, 2000.

Lambert, A., Read, W. G., Livesey, N. J., Santee, M. L., Manney, G. L., Froidevaux, L., Wu, D. L., Schwartz, M. J., Pumphrey, H. C., Jimenez, C., Nedoluha, G. E., Cofield, R. E., Cuddy, D. T., Daffer, W. H., Drouin, B. J., Fuller, R. A., Jarnot, R. F., Knosp, B. W., Pickett, H. M., Perun, V. S., Snyder, W. V., Stek, P. C., Thurstans, R. P., Wagner, P. A., Waters, J. W., Jucks, K. W., Toon, G. C., Stachnik, R. A., Bernath, P. F., Boone, C. D., Walker, K. A., Urban, J., Murtagh, D., Elkins, J. W., and Atlas, E.: Validation of the Aura Microwave Limb Sounder middle atmosphere water vapor and nitrous oxide measurements, J. Geophys. Res., 112, D24S36, doi:10.1029/2007JD008724, 2007.

Lambert, A., Santee, M. L., Wu, D. L., and Chae, J. H.: A-train CALIOP and MLS observations of early winter Antarctic polar stratospheric clouds and nitric acid in 2008, Atmos. Chem. Phys., 12, 2899-2931, doi:10.5194/acp-12-2899-2012, 2012.

Livesey, N. J., Read, W. G., Froidevaux, L., Lambert, A., Manney, G. L., Pumphrey, H. C., Santee, M. L., Schwartz, M. J., Wang, S., Cofield, R. E., Cuddy, D. T., Fuller, R. A., Jarnot, R. F., Jiang, J. H., Knosp, B. W., Stek, P. C., Wagner, P. A., and $\mathrm{Wu}, \mathrm{D}$. L.: Version 3.3 Level 3 data quality and description document, Tech. Rep. JPL D-33509, Jet Propulsion Laboratory, http://mls.jpl.nasa.gov, last access: 15 January 2013, 2011.

Luo, B. P., Peter, T., Fueglistaler, S., Wernli, H., Wirth, M., Kiemle, C., Flentje, H., Yushkov, V. A., Khattatov, V., Rudakov, V., Thomas, A., Borrmann, S., Toci, G., Mazzinghi, P., Beuermann, J., Schiller, C., Cairo, F., Di Donfrancesco, G., Adriani, A., Volk, C. M., Strom, J., Noone, K., Mitev, V., MacKenzie, R. A., Carslaw, K. S., Trautmann, T., Santacesaria, V., and Stefanutti, L.: Dehydration potential of ultrathin clouds at the tropical tropopause, Geophys. Res. Lett., 30, 1557, doi:10.1029/2002GL016737, 2003a.

Luo, B. P., Voigt, C., Fueglistaler, S., and Peter, T.: Extreme NAT supersaturations in mountain wave ice PSCs: A clue to NAT formation, J. Geophys. Res., 108, 4441, doi:10.1029/2002JD003104, $2003 b$.

Manney, G. L., Santee, M. L., Rex, M., Livesey, N. J., Pitts, M. C., Veefkind, P., Nash, E. R., Wohltmann, I., Lehmann, R., Froidevaux, L., Poole, L. R., Schoeberl, M. R., Haffner, D. P., Davies, J., Dorokhov, V., Gernandt, H., Johnson, B., Kivi, R., Kyro, E., Larsen, N., Levelt, P. F., Makshtas, A., McElroy,
C. T., Nakajima, H., Concepcion Parrondo, M., Tarasick, D. W., von der Gathen, P., Walker, K. A., and Zinoviev, N. S.: Unprecedented Arctic ozone loss in 2011, Nature, 478, 469-475, doi:10.1038/nature10556, 2011.

Marcolli, C., Gedamke, S., Peter, T., and Zobrist, B.: Efficiency of immersion mode ice nucleation on surrogates of mineral dust, Atmos. Chem. Phys., 7, 5081-5091, doi:10.5194/acp-7-50812007, 2007.

Maturilli, M. and Dörnbrack, A.: Polar stratospheric ice cloud above Spitsbergen, J. Geophys. Res., 111, D18210, doi:10.1029/2005JD006967, 2006.

McKenna, D. S., Konopka, P., Grooß, J.-U., Günther, G., Müller, R., Spang, R., Offermann, D., and Orsolini, Y.: A new Chemical Lagrangian Model of the Stratosphere (CLaMS) - 1. Formulation of advection and mixing, J. Geophys. Res., 107, 4309, doi:10.1029/2000JD000114, 2002.

Meilinger, S. K., Koop, T., Luo, B. P., Huthwelker, T., Carslaw, K. S., Krieger, U., Crutzen, P. J., and Peter, T.: Size-dependent stratospheric droplet composition in lee wave temperature fluctuations and their potential role in PSC freezing, Geophys. Res. Lett., 22, 3031-3034, doi:10.1029/95GL03056, 1995.

Mishchenko, M. I., Travis, L. D., and Mackowski, D. W.: T-Matrix Computations of Light Scattering by Nonspherical Particles: A Review (Reprinted from vol 55, pg 535-575, 1996), J. Quant. Spectrosc. Radiat. Transf., 111, 1704-1744, doi:10.1016/00224073(96)00002-7, 2010.

Müller, R., Peter, T., Crutzen, P. J., Oelhaf, H., Adrian, G. P., Clarmann, T., Wegner, A., Schmidt, U., and Lary, D.: Chlorine chemistry and the potential for ozone depletion in the Arctic stratosphere in the winter of 1991/92, Geophys. Res. Lett., 21, 1427 1430, doi:10.1029/94GL00465, 1994.

Murphy, D. M. and Gary, B. L.: Mesosclae Temperature Fluctuations and Polar Stratospheric Clouds, J. Atmos. Sci., 52, 1753-1760, doi:10.1175/15200469(1995)052<1753:MTFAPS>2.0.CO;2, 1995.

Nedoluha, G. E., Bevilacqua, R. M., Hoppel, K. W., Daehler, M., Shettle, E. P., Hornstein, J. H., Fromm, M. D., Lumpe, J. D., and Rosenfield, J. E.: POAM III measurements of dehydration in the Antarctic lower stratosphere, Geophys. Res. Lett., 27, 16831686, doi:10.1029/1999GL011087, 2000.

Peter, T. and Grooß, J.-U.: Chapter 4: Polar Stratospheric Clouds and Sulfate Aerosol Particles: Microphysics, Denitrification and Heterogeneous Chemistry, in: Stratospheric Ozone Depletion and Climate Change, Roy. Soc. Chem., 108-144, doi:10.1039/9781849733182-00108, 2012.

Pitts, M. C., Thomason, L. W., Poole, L. R., and Winker, D. M.: Characterization of Polar Stratospheric Clouds with spaceborne lidar: CALIPSO and the 2006 Antarctic season, Atmos. Chem. Phys., 7, 5207-5228, doi:10.5194/acp-7-5207-2007, 2007.

Pitts, M. C., Poole, L. R., and Thomason, L. W.: CALIPSO polar stratospheric cloud observations: second-generation detection algorithm and composition discrimination, Atmos. Chem. Phys., 9, 7577-7589, doi:10.5194/acp-9-7577-2009, 2009.

Pitts, M. C., Poole, L. R., Lambert, A., and Thomason, L. W.: An assessment of CALIOP polar stratospheric cloud composition classification, Atmos. Chem. Phys., 13, 2975-2988, doi:10.5194/acp-13-2975-2013, 2013.

Pitts, M. C., Poole, L. R., Dörnbrack, A., and Thomason, L. W.: The 2009-2010 Arctic polar stratospheric cloud season: a 
CALIPSO perspective, Atmos. Chem. Phys., 11, 2161-2177, doi:10.5194/acp-11-2161-2011, 2011.

Ploeger, F., Konopka, P., Günther, G., Grooß, J.-U., and Müller, R.: Impact of the vertical velocity scheme on modeling transport in the tropical tropopause layer, J. Geophys. Res., 115, D03301, doi:10.1029/2009JD012023, 2010.

Pommereau, J.-P., Goutail, F., Lefèvre, F., Pazmino, A., Adams, C., Dorokhov, V., Eriksen, P., Kivi, R., Stebel, K., Zhao, X., and van Roozendael, M.: Why unprecedented ozone loss in the Arctic in 2011? Is it related to climate change?, Atmos. Chem. Phys., 13, 5299-5308, doi:10.5194/acp-13-5299-2013, 2013.

Read, W. G., Lambert, A., Bacmeister, J., Cofield, R. E., Christensen, L. E., Cuddy, D. T., Daffer, W. H., Drouin, B. J., Fetzer, E., Froidevaux, L., Fuller, R., Herman, R., Jarnot, R. F., Jiang, J. H., Jiang, Y. B., Kelly, K., Knosp, B. W., Kovalenko, L. J., Livesey, N. J., Liu, H.-C., Manney, G. L., Pickett, H. M., Pumphrey, H. C., Rosenlof, K. H., Sabounchi, X., Santee, M. L., Schwartz, M. J., Snyder, W. V., Stek, P. C., Su, H., Takacs, L. L., Thurstans, R. P., Vömel, H., Wagner, P. A., Waters, J. W., Webster, C. R., Weinstock, E. M., and Wu, D. L.: Aura Microwave Limb Sounder upper tropospheric and lower stratospheric $\mathrm{H}_{2} \mathrm{O}$ and relative humidity with respect to ice validation, J. Geophys. Res., 112, D24S35, doi:10.1029/2007JD008752, 2007.

Rosen, J. M. and Kjome, N. T.: Backscattersonde: a new instrument for atmospheric aerosol research, Appl. Opt., 30, 1552-1561, doi:10.1364/AO.30.001552, 1991.

Santee, M. L., Lambert, A., Read, W. G., Livesey, N. J., Cofield, R. E., Cuddy, D. T., Daffer, W. H., Drouin, B. J., Froidevaux, L., Fuller, R. A., Jarnot, R. F., Knosp, B. W., Manney, G. L., Perun, V. S., Snyder, W. V., Stek, P. C., Thurstans, R. P., Wagner, P. A., Waters, J. W., Muscari, G., de Zafra, R. L., Dibb, J. E., Fahey, D. W., Popp, P. J., Marcy, T. P., Jucks, K. W., Toon, G. C., Stachnik, R. A., Bernath, P. F., Boone, C. D., Walker, K. A., Urban, J., and Murtagh, D.: Validation of the Aura Microwave Limb Sounder $\mathrm{HNO}_{3}$ measurements, J. Geophys. Res., 112, D24S40, doi:10.1029/2007JD008721, 2007.

Tolbert, M. A. and Toon, O. B.: Solving the PSC Mystery, Science, 292, 61-63, doi:10.1126/science.1060083, 2001.

Voigt, C., Schlager, H., Luo, B. P., Dörnbrack, A., Roiger, A., Stock, P., Curtius, J., Vössing, H., Borrmann, S., Davies, S., Konopka, P., Schiller, C., Shur, G., and Peter, T.: Nitric Acid Trihydrate (NAT) formation at low NAT supersaturation in Polar Stratospheric Clouds (PSCs), Atmos. Chem. Phys., 5, 13711380, doi:10.5194/acp-5-1371-2005, 2005.

Vömel, H., Rummukainen, M., Kivi, R., Karhu, J., Turunen, T., Kyrö, E., Rosen, J., Kjome, N., and Oltmans, S.: Dehydration and sedimentation of ice particles in the Arctic stratospheric vortex, Geophys. Res. Lett., 24, 795-798, doi:10.1029/97GL00668, 1997.

Vömel, H., David, D. E., and Smith, K.: Accuracy of tropospheric and stratospheric water vapor measurements by the cryogenic frost point hygrometer: Instrumental details and observations, J. Geophys. Res., 112, D08305, doi:10.1029/2006JD007224, $2007 \mathrm{a}$.

Vömel, H., Yushkov, V., Khaykin, S., Korshunov, L., Kyrö, E., and Kivi, R.: Intercomparisons of stratospheric water vapor sensors: FLASH-B and NOAA/CMDL frost-point hygrometer, J. Atmos. Ocean. Technol., 24, 941-952, doi:10.1175/JTECH2007.1, 2007 b.
Vömel, H., Oltmans, S. J., Hofmann, D. J., Deshler, T., and Rosen, J. M.: The evolution of the dehydration in the Antarctic stratospheric vortex, J. Geophys. Res., 100, 13919-13926, doi:10.1029/95JD01000, 1995.

von Hobe, M., Bekki, S., Borrmann, S., Cairo, F., D’Amato, F., Di Donfrancesco, G., Dörnbrack, A., Ebersoldt, A., Ebert, M., Emde, C., Engel, I., Ern, M., Frey, W., Genco, S., Griessbach, S., Grooß, J.-U., Gulde, T., Günther, G., Hösen, E., Hoffmann, L., Homonnai, V., Hoyle, C. R., Isaksen, I. S. A., Jackson, D. R., Jánosi, I. M., Jones, R. L., Kandler, K., Kalicinsky, C., Keil, A., Khaykin, S. M., Khosrawi, F., Kivi, R., Kuttippurath, J., Laube, J. C., Lefèvre, F., Lehmann, R., Ludmann, S., Luo, B. P., Marchand, M., Meyer, J., Mitev, V., Molleker, S., Müller, R., Oelhaf, H., Olschewski, F., Orsolini, Y., Peter, T., Pfeilsticker, K., Piesch, C., Pitts, M. C., Poole, L. R., Pope, F. D., Ravegnani, F., Rex, M., Riese, M., Röckmann, T., Rognerud, B., Roiger, A., Rolf, C., Santee, M. L., Scheibe, M., Schiller, C., Schlager, H., Siciliani de Cumis, M., Sitnikov, N., Søvde, O. A., Spang, R., Spelten, N., Stordal, F., Sumińska-Ebersoldt, O., Ulanovski, A., Ungermann, J., Viciani, S., Volk, C. M., vom Scheidt, M., von der Gathen, P., Walker, K., Wegner, T., Weigel, R., Weinbruch, S., Wetzel, G., Wienhold, F. G., Wohltmann, I., Woiwode, W., Young, I. A. K., Yushkov, V., Zobrist, B., and Stroh, F.: Reconciliation of essential process parameters for an enhanced predictability of Arctic stratospheric ozone loss and its climate interactions (RECONCILE): activities and results, Atmos. Chem. Phys., 13, 92339268, doi:10.5194/acp-13-9233-2013, 2013.

Warren, S. G.: Optical constants of ice from the ultraviolet to the microwave, Appl. Opt., 23, 1206-1225, doi:10.1364/AO.23.001206, 1984.

Waters, J. W., Froidevaux, L., Harwood, R. S., Jarnot, R. F., Pickett, H. M., Read, W. G., Siegel, P. H., Cofield, R. E., Filipiak, M. J., Flower, D. A., Holden, J. R., Lau, G. K. K., Livesey, N. J., Manney, G. L., Pumphrey, H. C., Santee, M. L., Wu, D. L., Cuddy, D. T., Lay, R. R., Loo, M. S., Perun, V. S., Schwartz, M. J., Stek, P. C., Thurstans, R. P., Boyles, M. A., Chandra, K. M., Chavez, M. C., Chen, G. S., Chudasama, B. V., Dodge, R., Fuller, R. A., Girard, M. A., Jiang, J. H., Jiang, Y. B., Knosp, B. W., LaBelle, R. C., Lam, J. C., Lee, K. A., Miller, D., Oswald, J. E., Patel, N. C., Pukala, D. M., Quintero, O., Scaff, D. M., Van Snyder, W., Tope, M. C., Wagner, P. A., and Walch, M. J.: The Earth Observing System Microwave Limb Sounder (EOS MLS) on the Aura satellite, IEEE Trans. Geosci. Remote Sens., 44, 10751092, doi:10.1109/TGRS.2006.873771, 2006.

Winker, D. M., Hunt, W. H., and McGill, M. J.: Initial performance assessment of CALIOP, Geophys. Res. Lett., 34, L19803, doi:10.1029/2007GL030135, 2007.

Yushkov, V., Astakhov, V., and Merkulov, S.: Optical balloon hygrometer for upper-troposphere and stratosphere water vapor measurements, in: Society of Photo-Optical Instrumentation Engineers (SPIE) Conference Series, vol. 3501 of "Society of Photo-Optical Instrumentation Engineers (SPIE) Conference Series", 439-445, 1998. 